Vargas Zamora, J. y Chacón Hidalgo, M. (2022). ESCASEZ DE MONEDA, MONEDA PROVISIONALES, RESELLADO DE EXTRANJERAS Y EMISIONES DE LA REPÚBLICA, COSTA RICA (1821-1848). Revista Herencia, 35(1), enero-junio, 12-43.

\title{
ESCASEZ DE MONEDA, MONEDAS PROVISIONALES, RESELLADO DE EXTRANJERAS y EMISIONES DE LA REPÚBLICA, COSTA RICA (1821-1848)
}

The scarcity of coins, provisional coinage, foreign coin counter-stamping and issues of the Republic, Costa Rica (1821-1848)

\author{
José A. Vargas Zamora* \\ Universidad de Costa Rica, Costa Rica \\ jose.vargas@ucr.ac.cr \\ Manuel B. Chacón Hidalgo** \\ Museos del Banco Central, Costa Rica \\ CHACONHM@bccr.fi.cr
}

Recibido: 15-09-2021

Aprobado: 09-11-2021

* PhD. en Oceanografía Biológica. Profesor Emérito. Escuela de Biología, Universidad de Costa Rica, Costa Rica.

** Doctor en Historia. Curador de la Colección Numismática. Museos del Banco Central de Costa Rica. Costa Rica.

\section{RESUMEN}

Desde tiempos coloniales hasta la mitad del siglo XIX, la escasez de circulante, en particular de baja denominación, fue un problema en Costa Rica. Como resultado, la semilla de cacao se autorizó como dinero a principios del siglo XVIII. Durante la década de 1840, el trabajo y producción en las plantaciones de café fueron los motores de la economía, y la demanda por monedas aumentó. Se permitió la circulación de monedas extranjeras para mitigar la escasez. Sin embargo, muchas eran de bajo contenido de metal precioso o eran falsificaciones. Monedas británicas, españolas, americanas y macuquinas coloniales se ensayaron y aquellas que cumplían los estándares locales de calidad se estamparon con sellos y fueron autorizadas para circular junto con monedas acuñadas localmente. Los sellos incluían figuras como árboles, una planta de tabaco, una estrella, un león y mujeres jóvenes. En este estudio se expone un vistazo de esas monedas desde 1821 hasta la fundación de la República en 1848 y los posibles significados de símbolos grabados en ellas.

Palabras clave: monedas reselladas; macuquinas; cacao; tabaco; café; encina.

\section{ABSTRACT}

From colonial times to the mid XIX century the scarcity of currency, particularly that of lower denominations, was a problem in Costa Rica. As a result, cocoa seeds were authorized as money at the beginning of the $18^{\text {rh }}$ century. In the 1840-decade coffee plantation labor and production became the motors of the economy and the demand for coins increased. Foreign coins were allowed to circulate to relieve the shortage. However, many were of low precious metal content or were counterfeits. British, Spanish, American, and colonial cobs were assayed and those that met the local standards of quality were engraved with seals and authorized to circulate together with locally minted pieces. The seals included figures, such as trees, a tobacco plant, a star, a lion, and young women. In this paper we provide an overview of these coins from 1821 to the foundation of the Republic in 1848 and the possible meanings of symbols engraved on them.

Key words: counter-stamped coins; cobs; cocoa; tobacco; coffee; oak. 
Revista Herencia, Vol. 35 (1), enero-junio, 2022.

\section{Introducción}

El 25 de septiembre de 1502, durante su cuarto viaje al Nuevo Mundo, la flota de cuatro naves del almirante Cristóbal Colón, acompañado de su hijo Fernando y de su hermano Bartolomé, echó anclas al abrigo de una isleta a la que bautizó La Huerta, al frente de una costa que llamó Cariay. Hoy se acepta que la isleta es La Uvita al frente del puerto de Limón, en la costa Caribe de Costa Rica, América Central (Vargas Zamora et al., 2011).

Durante la época colonial, Costa Rica formó parte de la Capitanía General de Guatemala. Era la provincia que se ubicaba en el extremo meridional y constituía el límite del Virreinato de la Nueva España. Sus límites fueron establecidos por la Corona española en el siglo XVI, durante el reinado de Felipe II. Por medio de la Real Cédula de $1^{\circ}$ de diciembre de 1573 se le fijó el límite norte a la provincia en las bocas del río Desaguadero o San Juan y se estableció que tal río pertenecería a Nicaragua. Con ello, los límites quedaron establecidos de la siguiente manera: al norte con Nicaragua (más tarde la Intendencia de León), el Corregimiento de Nicoya (más tarde el Partido de Nicoya) y el río Desaguadero o San Juan. Al sureste, con la provincia de Veragua, territorio que formaba parte del Virreinato de Nueva Granada (anteriormente llamada Tierra Firme).

La sociedad colonial costarricense se caracterizó por ser agraria. Costa Rica se integró al comercio intercolonial a finales del siglo XVI y principios del XVII, a través de la exportación de víveres a Panamá (cerdos, bizcocho, grasa, cuero, maíz, gallinas, trigo, ajos, culantro, etc.) y mulas. Aun cuando se dio la producción y exportación de cacao, tabaco y ganado, entre otros, tanto a Panamá como a Nicaragua, El Salvador y Guatemala, el período colonial en Costa Rica se caracterizó por la constante escasez de moneda y la poca que circulaba ingresaba a este territorio como producto del comercio con otras colonias del Imperio Español. La escasez de circulante, especialmente de las monedas de plata de baja denominación necesarias para las transacciones cotidianas, era un problema crónico de la economía costarricense durante la colonia y hasta avanzado el siglo XIX.

Desde tiempos coloniales el sistema monetario utilizado en Costa Rica fue bimetálico (oro y plata) hasta mediados del siglo XIX. En las emisiones de monedas posteriores a la Independencia (1821), y hasta la actualidad, se optó por eliminar el grabado del busto del gobernante de turno y sustituirlo por otros símbolos con diversos significados. Varias especies vegetales fueron grabadas, pero los decretos respectivos generalmente no aportan datos sobre los nombres de esas especies y las razones de su escogencia.

En este escrito se proporciona un vistazo a los esfuerzos que, entre 1821 y 1848 , fueron hechos para habilitar y acuñar moneda, así como algunas hipótesis sobre los significados de los símbolos en ellas.

\section{El siglo XVIII}

En Costa Rica, varios núcleos de población se establecen alrededor de ayudas de parroquias hacia el oeste de la ciudad de Cartago (fundada en 1563), como Cubujuquí (1717, hoy Heredia), la Boca del Monte (1737, hoy San José) y La Lajuela (1782, hoy Alajuela) en la 
Revista Herencia, Vol. 35 (1), enero-junio, 2022.

ruta hacia el Pacífico (Monge-Alfaro, 1962, p. 126-133). Tal como lo indican Molina y Palmer (2017, p. 41) en estos pueblos los vecinos principales ocupaban puestos civiles, militares y eclesiásticos. Algunos alquilaban terrenos a los campesinos y la mayoría debía cultivar lo básico para su subsistencia y productos para la venta o el trueque (Sáenz-Maroto, 1970). Otros eran dueños de plantaciones de cacao (Theobroma cacao) en Matina, costa Caribe, o poseían haciendas de ganado en la región de Nicoya y Guanacaste en la costa del Pacífico para la producción de carne y el comercio de cueros.

Durante este período Costa Rica no tuvo casa de acuñación de moneda, por lo que las fuentes de moneda metálica estaban relacionadas con el pago de los funcionarios administrativos coloniales, los del clero y las posibilidades del comercio intercolonial. Desde el siglo XVII, Costa Rica mantuvo un importante comercio de víveres y mulas con Panamá, que representó una de sus principales fuentes de moneda metálica durante el período colonial, tanto por la venta directa de los productos como por los pagos por adelantado a manera de crédito para el avío de las haciendas, lo cual se hacía especialmente en moneda de plata (Archivo Nacional de Costa Rica, Cartago, $\mathrm{N}^{\circ} 838,1689$, p. 12). Otros productos se incorporaron al comercio colonial, como el cacao en la segunda mitad del siglo XVII e inicios del siglo XVIII y el tabaco en la segunda mitad del mismo siglo, los cuales fueron una importante fuente para el ingreso de moneda metálica a la provincia.

Si bien, la escasez de moneda fue un problema estructural de la economía de la provincia en particular, esta siempre circuló aunque de manera regulada, por parte de aquellos grupos que tuvieron acceso a ella, por lo que la concentración de la misma estuvo en los sectores económicos ligados al comercio, la administración colonial y la iglesia, quienes la acapararon para utilizarla en actividades productivas, comerciales y de crédito, dejando a otros grupos fuera del acceso a la moneda metálica o al manejo de muy pequeñas cantidades lo que no permitía el ahorrar o invertir en actividades productivas.

Como ejemplo, un grupo social, que debido a sus actividades logró controlar parte de la escasa moneda, eran los arrieros, quienes se dedicaron, desde fines del siglo XVI, a la cría y venta de mulas, así como al transporte a lomo de mulas de productos agrícolas, cueros y algunas manufacturas a los mercados locales y al exterior de Costa Rica. Según MolinaMontes de Oca (2005, p. 443) ante la escasez de moneda, la prosperidad de los arrieros estuvo fundamentada en el intercambio de mercaderías y en servir de intermediarios entre los productores que no disponían de medios de transporte ni capacidad comercial y los usuarios de las mercancías que trasegaban. El papel de los arrieros fue importante hasta principios del siglo XIX.

\section{El cacao como moneda}

Al principio del siglo XVIII la escasez de monedas hacía difícil el comercio y ante la solicitud de varios vecinos, el 8 de julio de 1709, el gobernador Lorenzo de Granda y Balbín, emitió el siguiente decreto (Chacón-Hidalgo, 2008, p. 141):

...mando que de oi día de la fecha en adelante, todos los vecinos criadores de ganado, en quienes esta hecho el repartimiento del avasto de la carne, los que vendieren candelas, mais, dulse, sal, leña, manteca, javon, sevo, y demás cosas tocantes al mantenimiento resivan por ello, cacao, 
Revista Herencia, Vol. 35 (1), enero-junio, 2022.

siendo bueno dar y rresivir, pena, de diez pesos a dichos criadores y de sinco pesos a los que venden los demás jeneros mencionados lo contrario haciendo...

El cacao ya había sido utilizado como moneda por los indígenas desde tiempos anteriores a la colonia (Burzio, 1958, p. 33). Sin embargo, se tuvo que definir su equivalencia con la moneda de plata y, por ejemplo, en 1728 el gobernador Baltasar de Valderrama estableció la tasa de cambio del cacao en cien almendras por un real de plata (Chacón-Hidalgo, 2008, $\mathrm{p} 142)$.

Según lo indica Molina-Montes de Oca (2005, p. 363), el uso legal de semillas de cacao como moneda, hizo que los productores pagaran a los arrieros con cacao el costo del flete para traer ese producto desde las plantaciones en Matina hasta el centro del país y fuera de este. Los arrieros negociaban otros productos utilizando como pago el cacao, o lo intercambiaban por mulas en los pueblos de Esparza y Nicoya. Un aspecto muy importante en la dinámica de la economía del cacao es resaltado por Chacón-Hidalgo (2008, p.146):

Los productores y comerciantes de cacao también se dedicaron al contrabando, cambiando el cacao por productos manufacturados. En el mercado interno, el cacao utilizado como moneda les permitía obtener abastos y otros productos artesanales. Por otro lado, obtenían moneda de plata por concepto de la exportación de cacao, especialmente a Nicaragua, y por el contrabando, también a Nicaragua de productos importados como ropa y especias, entre otros, obtenidos de los comerciantes ingleses y holandeses en Matina.

Otro grupo primordial en el manejo de monedas fue el de los comerciantes de cacao, cuyo cultivo se extendió en la zona de Matina después de 1660 y tuvo su auge entre 1727 y 1747 con exportaciones a Nicaragua, algunas islas del Caribe, Portobelo y Cartagena (Molina y Palmer, 2017, p. 33). El primer censo de plantaciones de cacao se llevó a cabo en 1678 y contabilizó 52 propietarios al cuidado de 136.730 árboles, con un promedio de 2.600 árboles por plantación (McLeod, 1996, p. 80).

Un ejemplo del capital acumulado por algunos comerciantes de cacao y criadores de mulas es el mortual del sargento mayor Antonio Zamora, fechada en 1716. Según lo indican Bolaños Villalobos y Arrea Siermann (1999, p 91-92, con base en el documento ANCR, Protocolos de Cartago $\mathrm{N}^{0}$ 878), el sargento poseía en Barba, Heredia, algunas armas y numerosos objetos de uso en agricultura, además de dos casas de adobes, algunos muebles, un trapiche, 200 reses, 33 mulas, 18 yeguas, 12 yuntas de bueyes, cuatro quintales de algodón, seis embarques de cacao de primera de Suerre por valor de 150 pesos, 10 géneros de cacao remitidos a León, Nicaragua, y ocho tercios en poder de su hermano, el alférez Gregorio Zamora, en León, por valor de 100 pesos. Como contraste, solo encontraron tres camisas, tres sombreros, dos pares de medias de seda, un traje y una casaca de felpa y otra de Bretaña con encajes. El mortual también anota la suma de 450 pesos en plata acuñada, una fortuna para la época. Es interesante que no se mencionan monedas (escudos) de oro.

Otras operaciones comerciales se negociaban con cacao; un ejemplo lo ilustra CarranzaAstúa (2014, p. 11), con un documento que data de 1789 y considerado como el prototipo de papel moneda más antiguo conocido en Costa Rica. Por sus endosos tuvo una función similar a una letra de cambio, está escrito a mano en un papel no oficial (sin impuestos coloniales), y dice: 
Revista Herencia, Vol. 35 (1), enero-junio, 2022.

Cartago, 21 de setiembre de 1789. Digo yo, Jph (Joseph) de la Concepción Valerín que debo al Sr. Dn Ignacio Llorent cincuenta y cinco ps (pesos) de cacao bueno de dar y recibir, los que he de entregar a su disposición puestos en el valle de Matina sin flete en todo el mes de octubre próximo de este año, y al cumplimiento de lo otro obligo mis bienes habidos y por haber y para que conste doy el presente, que por no saber firmar lo hará a mi ruego el infrascripto. Por el otorgante. Jph Joachim coronel

El documento fue endosado en dos ocasiones, la primera dice: Cartago enero 28, 1790. Páguese por mí los cincuenta y cinco ps en cacao a Sr Don A Fgndo de Rucavado. Firma Ignacio Llorent. La segunda en el reverso, sin fecha: Por A de la Concepción Valerín, ilegible 55. El cultivo del cacao fue importante durante los siglos XVII y XVIII; luego va cediendo importancia ante otro cultivo, el del tabaco y este, a su vez, al del café, en el siglo XIX.

Es importante mencionar que el uso de cacao como moneda fue complementario al de moneda de plata y no sustitutivo (Chacón-Hidalgo, 2008, p. 143). La apertura forzosa del sistema monetario para la utilización oficial del cacao como moneda, no sólo obedeció al problema de la pobreza por el escaso comercio y el poco ingreso de moneda metálica. Con un discurso basado en una pobreza generalizada de la provincia por la falta de comercio y por ende de moneda necesaria para obtener los productos básicos para la subsistencia, la burocracia provincial colonial, muchos de ellos propietarios de plantaciones de cacao y comerciantes, encontraron en el mecanismo de la obligación de la aceptación forzosa del cacao como moneda en todas las transacciones, bajo pena de multas, la manera de colocar el cacao en un "nuevo mercado", ante la caída del mercado de Portobelo y las dificultades para la exportación a Nicaragua. La estrategia política tuvo éxito y con ella los comerciantes y productores de cacao limitaron a la mayoría de la población y a los pequeños comerciantes de tienda como competidores por el acceso por la moneda metálica de plata (ChacónHidalgo, 2008).

En las postrimerías del siglo XVIII decayó la expansión de la producción y el comercio en Centroamérica. El añil centroamericano fue incapaz de competir con los precios más bajos ofrecidos por productores de otras partes, lo cual provocó su estancamiento. A pesar de que hubo un gran desarrollo del comercio interregional por el Mar del Sur o Pacífico en el siglo XVIII, con una importante participación de Perú, Chile, Guayaquil y Panamá, el mercado regional de Centroamérica, aunque participó de dicho comercio, fue poco dinámico (León, 2001, p. 321).

A inicios del siglo XIX, la moneda escaseaba en Hispanoamérica y por ende en Costa Rica, debido a los términos de intercambio desiguales con el exterior que provocaban un déficit en la balanza comercial. En Costa Rica, el poco metálico que ingresaba lo hacía como producto del pago a funcionarios civiles, militares y eclesiásticos, de los gastos en que incurría la Factoría de Tabacos, cuyo volumen de exportación y de ingresos había bajado como consecuencia de la eliminación de la exclusividad de siembra del tabaco en la década de 1790, y por la renta de las otras exportaciones que el extranjero cancelaba monetariamente y no con mercancía importada (Molina, 1988, p. 192). Sin embargo, la moneda continuó siendo escasa y el capital continuó estando compuesto por tierra y ganado (Archivo Nacional de Costa Rica, Complemento colonial, No 509, 1802, p. 5). 
Revista Herencia, Vol. 35 (1), enero-junio, 2022.

La relación comercial con Panamá continuó siendo importante para el ingreso de moneda durante las primeras dos décadas del siglo XIX. Por esta razón, en marzo de 1821, meses antes de la independencia, el Ayuntamiento de Alajuela resolvió dejar circular la moneda conocida como insurgente, a solicitud del Procurador Síndico de esa ciudad, señor Juan Antonio Alfaro (Archivo Nacional de Costa Rica, Municipal No 139, 1821, p. 5). Este manifestó la conveniencia de que en esta Provincia circule dicha moneda dada la escasez de medios de cambio.

\section{La primera mitad del siglo XIX}

Proclamada la independencia, una de las primeras preocupaciones del naciente estado de Costa Rica fue organizar su sistema monetario. Mientras esto sucedía, Costa Rica, al igual que muchos de los nuevos estados americanos independizados, continuó utilizando el sistema español heredado de la colonia, con el real como unidad monetaria para la plata y el escudo para el oro. De igual forma, se comenzó a plantear la necesidad de establecer una Casa de Cuño para fabricar moneda propia, debido a la escasez de numerario, la baja calidad de muchas de las monedas coloniales que circulaban y la búsqueda de un elemento que representara soberanía del nuevo estado con respecto al imperio español y a cualquier otro.

En Costa Rica, la primera mitad del siglo XIX estuvo marcada por varios acontecimientos que tendrían influencia directa en la economía del país y en la necesidad de contar con más disponibilidad de monedas. Estos fueron: 1. El inicio del cultivo del café alrededor de 1800 y su conversión años después en el motor de la economía. 2. El descubrimiento en 1815 de oro en los Montes del Aguacate en la ruta al Pacífico. 3. Las declaraciones en 1821 de la Independencia de España por parte de Guatemala (15 de septiembre) y por Costa Rica (29 de octubre). 4. La integración, entre 1824 y 1838, de Costa Rica como Estado miembro de la República Federal con sede en Guatemala. 5. La agregación voluntaria a Costa Rica en 1824 del Partido de Nicoya, cuyo territorio formaba gran parte de la actual provincia de Guanacaste. 6. La emisión de moneda de oro provisional en 1825. 7. El establecimiento de la Casa Moneda en 1828 y sus primeras emisiones. 8. La habilitación de moneda extranjera mediante resellos. 9. La fundación de la República en 1848 y la acuñación de sus nuevas monedas. 10. El lento crecimiento de la población: de 52,591 en 1801, a 93.871 en 1844 (Thiel, 1902, p. 30).

\section{Las primeras emisiones del Estado de Costa Rica, sus grabados y su simbología}

Después de la Independencia, el gobierno de Costa Rica buscó la forma de acuñar su propia moneda o de habilitar moneda extranjera. En 1822 se acuerda autorizar, con el resello de una corona imperial, el uso de monedas de ocho reales extranjeras (Murillo, 2004, p. 31). De estas monedas que circularon hasta 1833 se conoce un único ejemplar (Chacón-Hidalgo, 2018, p. 19).

El descubrimiento en 1815 de oro en los Montes del Aguacate desató una avalancha de denuncios de minas. Uno de los denunciantes fue Manuel Alvarado, quien construyó en 1822 un ingenio para el procesamiento del mineral y la extracción del oro. Este complejo

ISSN: 1659-0066 
Revista Herencia, Vol. 35 (1), enero-junio, 2022.

tenía el nombre de Ingenio de Metales San José de los Horcones. Don Manuel se asoció con el ingeniero de minas y español, Mateo Urandurraga, quien le hizo mejoras al ingenio (Chacón-Hidalgo, 2018, p. 40-47). El 19 de febrero de 1825 se estableció una Casa de Moneda Provisional y esta quedó a cargo de don Mateo. Al tomar ventaja de la disponibilidad de oro se acordó acuñar moneda en ese metal. Aun cuando estas emisiones mitigaron un poco la escasez de circulante, la moneda más escasa era la de plata, necesaria para las operaciones menores y para dar cambio por la de oro.

Esas monedas de oro no fueron bien recibidas debido a su tosca hechura y se descontinuó su acuñación ese mismo año. Igualmente, ese año se cerró la Casa de Moneda Provisional. No obstante, las monedas de Los Horcones circularon hasta 1833, cuando se retiraron (Chacón-Hidalgo, 2018, p. 40-47). Otra de las razones del descrédito era el árbol grabado, una palmera, y no un árbol típico como lo esperaban las autoridades federales en Guatemala. Según lo relata Jara $(2007$, p. 119) en su transcripción de un documento de 1825 de la Comisión del Gobierno de Costa Rica que analizó las monedas de Los Horcones, indica:

\begin{abstract}
...En la (moneda) de Guatemala aparece un árbol copado arriba, su vástago derecho, y sin ramas y en la nuestra se advierte una palma llena de ellas. Notable diferencia que hará que la nuestra no tenga crédito, pues deben ser uniformes las de los Estados del Centro, y la de Guatemala que ha corrido siempre debe ser la norma de todos ellas, pues ya aquella tiene de antemano conseguido el crédito.
\end{abstract}

Se ha incluido la imagen (Figura 1) del medio escudo de 1825, una de las escasas monedas sobrevivientes de Los Horcones.

Figura 1. A. Escudo del Estado de Costa Rica, 1823-1824 (Reconstrucción de Solera-Rodríguez, 1955, p.

7). B. Medio escudo (1/2 E), 1825. Diámetro $16 \mathrm{~mm}$ Peso 1.8 g. Emisión de la Casa de Moneda

Provisional. Ingenio de Metales San José de Los Horcones, Alajuela. Anverso: cinco montañas y sol en el cenit. En la orla, abreviada, República del Centro de América y fecha. Reverso: Palmera con palmas y valor. En la orla, abreviada: Libre Cresca Fecundo. C.R. (Costa Rica), M.U. (Mateo Urandurraga), 21 Q (oro 21 Quilates).

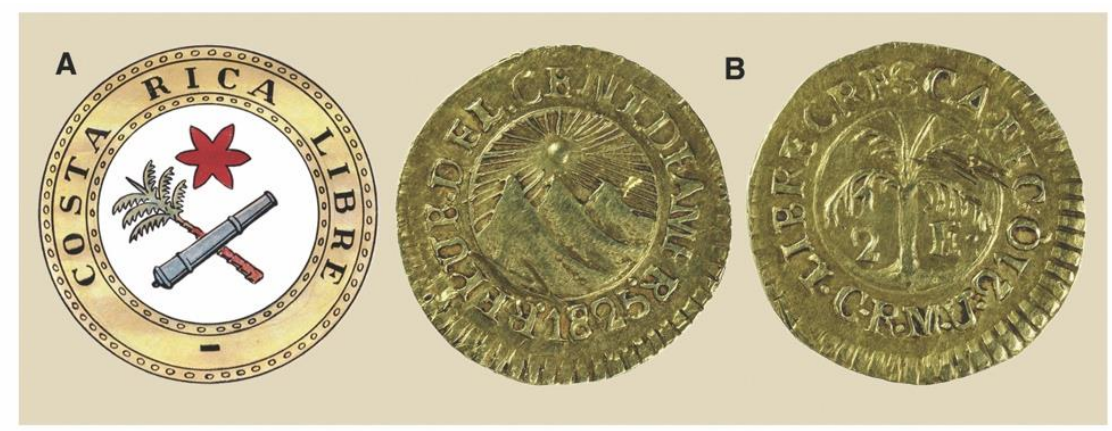

Fuente: Colección Museo BCCR.

Cabe preguntar, ¿por qué se grabó una palmera? y ¿cuál especie podría representar? Una de las razones para grabarla podría ser que ese árbol, con siete palmas, se incluyó en el primer escudo del Estado de Costa Rica (Figura 1), vigente entre el 10 de mayo de 1823 y el 6 de marzo de 1824 (Murillo, 2004, p. 22). Ese escudo fue sustituido el 2 de noviembre de 1824 por un nuevo diseño con otros símbolos (Solera Rodríguez, 1955, p. 69). No 
Revista Herencia, Vol. 35 (1), enero-junio, 2022.

obstante, según Murillo (2004, p. 15-16) el 19 de febrero de 1825 el jefe Supremo, además de establecer el cuño provisional, también dictó que la moneda llevaría tres volcanes, sol, y un árbol en forma de palmera.

Del mismo modo, se ha propuesto (Vargas-Zamora y Gómez-Laurito, 2006, p. 67) que la especie podría corresponder a la palmera datilera europea (Phoenix dactylifera) cuyas hojas (palmas) son símbolos de victoria asociada con la entrada triunfal de Jesucristo en Jerusalén (Juan, 12, 13: tomaron ramas de palma y salieron a su encuentro gritando ;Hosanna!). Es posible que la palmera, por ser un árbol fuerte ante los vientos y crecer con tronco recto se grabó como símbolo de la fortaleza y crecimiento con rectitud del nuevo Estado. El grabado de una palmera datilera en monedas data de tiempos antiguos. Representaciones en moneda de la Hispania Ulterior presentan un árbol de tronco recto y con tres o cuatro pares de palmas opuestas. Asimismo, hay representaciones antiguas de la hoja (palma) de la palmera (RuizLópez, 2020, p. 26-27).

\section{Las monedas de oro y plata (1829-1850) y el árbol}

La Casa de Moneda de Guatemala se fundó en 1733. En 1821, Guatemala decretó su independencia de España y esto fue seguido por los otros territorios de la antigua Capitanía, que incluían a Costa Rica. En 1823 se estableció la República Federal integrada por cinco territorios y en 1824 Guatemala, centro de gobierno de la República, acuñó sus primeras monedas federativas. Estas piezas tenían grabado en el anverso el escudo federal con cinco montañas representando cada una a uno de los estados miembros, un sol naciente en las de plata y un sol en el cenit en las de oro. En la orla República del Centro de América y la fecha. Igualmente, se grabó en el reverso para eliminar los símbolos de la monarquía y como emblema de la libertad (Artículo 4 del decreto del 19 de marzo de 1824 de la Asamblea Nacional Constituyente de las Provincias Unidas del Centro de América, Guatemala), un árbol joven, de tronco recto y copa globular, al cual se le augura que libre crezca fecundo (Lines, 1946, p. 14). Es oportuno mencionar que el árbol y el lema Libre Crezca Fecundo de las monedas fue adoptado en 1924 como escudo del Banco Nacional de Seguros (Hoy Instituto Nacional de Seguros). Curiosamente, el reglamento del Banco atribuye sin fundamento el árbol a la especie Enterolobium cyclocarpum cuando indica que se usará en el escudo el dibujo del árbol de Guanacaste que tenía la moneda de la federación centroamericana (Lines, 1946, p. 15).

Si bien los documentos no indican el nombre común del árbol, se argumenta popularmente, y por algunos autores como Raymond (1937, p. 45) y Wallace (1966, p. 10), que dicho árbol corresponde a una ceiba (Ceiba pentandra), especie abundante en la región centroamericana y sagrada para los indígenas (Vargas-Zamora y Gómez-Laurito, 2004, p. 158). Su alto tronco, que sobrepasa a veces los $50 \mathrm{~m}$ de altura conecta, según la tradición indígena, el cielo con el inframundo. Valerio-Garita (2019, p. 126) indica que el árbol federativo es un símbolo de libertad y liberalismo, pero no está relacionado con la especie sagrada de los mayas. El grabado de un árbol en las monedas centroamericanas tal vez estuvo influenciado por el uso de especies de árboles como símbolos de libertad asociados a la independencia de los Estados Unidos de América (1776) y de su forma de organización posterior de tipo federal. Entre esas especies destaca el olmo blanco (Ulmus americana) el 
Revista Herencia, Vol. 35 (1), enero-junio, 2022.

Tree of Liberty (Árbol de Libertad) bajo cuya copa se reunían en Boston los Hijos de la Libertad entre 1765 y 1775 (Harden, 1995, p. 75). También hubo siembras de árboles de libertad en Nueva Granada, especialmente en Cundinamarca entre 1813 y 1816 (Konig, 2014, p. 19).

\section{Las acuñaciones de monedas con el árbol}

En Costa Rica los esfuerzos por dotar al país de una casa de moneda culminaron el 13 de octubre de 1828 con el decreto que estableció, en el Estado de Costa Rica, la Casa de Moneda en San José, que inició operaciones en enero de 1829. Después de febrero de 1829, con el oro proveniente de los Montes del Aguacate, se acuñaron entre 1828 y 1831 monedas con troqueles fabricados en Guatemala y con fecha 1828. También, se emitieron hasta 1839 monedas con fechas 1833,1835 y 1837 , para un total de 29.787 piezas en denominaciones de 8 (onza), 4, 2, 1, y 1/2 escudos (Chacón-Hidalgo, 2018, p. 87).

Posteriormente, la Casa de Moneda acuñó monedas de oro de medio escudo (1843, 46, 47, 48 y 1849), un escudo (1844, 45, 46, 47, 48 y 1849), dos escudos (1846 y 1850) y cuatro escudos (1849). La falta de nuevos troqueles hizo que las monedas de 1848 a 1850 llevaran símbolos federales; no obstante, en 1848, se decretaron las nuevas monedas de Costa Rica como República independiente establecida ese año.

Tanto en las acuñaciones de oro como en las de plata, la Casa de Moneda se vio forzada a utilizar el modelo de moneda establecido por Guatemala y que incluye a un árbol (Figura. 2). 
Revista Herencia, Vol. 35 (1), enero-junio, 2022.

Figura 2. Casa de Moneda de San José. A. Un Peso (8 reales). 38 mm 26.8 g. Anverso: cinco montañas y sol figurado naciente. En la orla, República del Centro de América y año (1831).

Reverso: en el centro árbol de tallo recto y copa globular, a los flancos el valor (8. R.). En la orla, Libre Cresca Fecundo, C.R. (Costa Rica), F (Félix Mora), 10 D D $^{\mathrm{s}} 20 \mathrm{G}^{\mathrm{s}}$ (903 milésimas de plata).

B. Una onza. $36 \mathrm{~mm} 27.0$ g. Anverso: cinco montañas y sol figurado en el cenit. En la orla, República del Centro de América y año (1828). Reverso: en el centro un árbol de tallo recto y copa globular, a los flancos el valor (Ocho escudos, 8. E.). En la orla, Libre Cresca Fecundo, C. R. (Costa Rica), F (Félix Mora), $21 \mathrm{Q}^{\mathrm{s}}$ (oro 21 quilates).

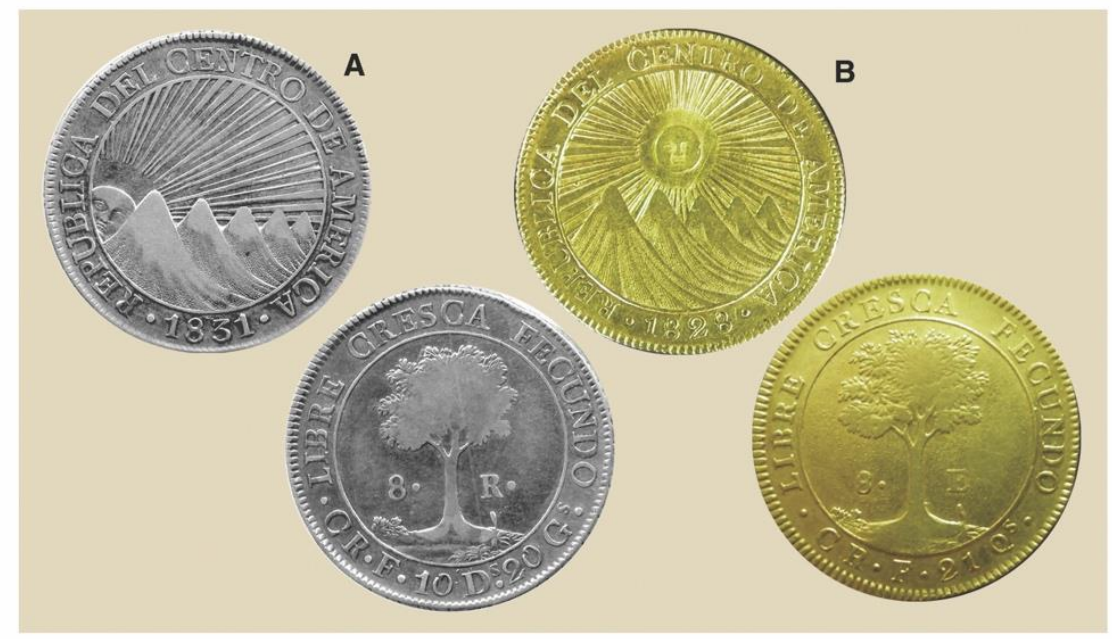

Fuente: Colección privada.

La escasez de metal hizo que las emisiones de monedas de plata sean menores y que, en las de ocho reales, en particular, se recurriera a la retroquelación de monedas extranjeras, lo que dio como resultado variación en el diámetro y peso de esas piezas. Se hicieron acuñaciones entre 1831 y 1839 en valores de ocho reales (un peso), un real y medio real, para un total estimado de 7.181 (Chacón-Hidalgo, 2018, p. 92).

\section{Las emisiones monetarias y la habilitación de la moneda extranjera 1841-1850}

La escasez de moneda fue un problema estructural de las economías americanas desde tiempos coloniales y durante la mayor parte del siglo XIX. Los esfuerzos de la Casa de Moneda de Costa Rica para dotar al país de moneda propia no resolvían el problema de la escasez de circulante, especialmente en el contexto del auge de la economía provocada por el aumento de las plantaciones de café que demandaban los pagos de mano de obra, la recolección de los frutos y el procesamiento del grano, así como las necesidades de un mercado interno en crecimiento. Para el caso de Costa Rica, desde tiempos coloniales, el escaso dinero circulante estaba integrado por una mezcla de monedas provenientes de diferentes países americanos y europeos, con los consiguientes problemas de equivalencias, diámetros, simbologías diversas, idiomas, falta de uniformidad en su contenido de plata u oro, y la introducción de monedas falsas, de modo que esto hizo necesario el tomar medidas para asegurar la legitimidad del circulante e identificarlas para uso local. 
Revista Herencia, Vol. 35 (1), enero-junio, 2022.

Para finales de la década de 1830, la pertenencia de Costa Rica a la República Federal no reportaba muchos beneficios, por lo que el jefe de Estado, el abogado don Braulio Carrillo, optó en 1838, por separar a Costa Rica de la Federación y declarar un Estado independiente. En noviembre de 1841, don Braulio decretó una ordenanza para que todas las monedas de plata extranjeras de tipo cordoncillo fueran presentadas a la Casa de Moneda para ser evaluadas (Murillo, 2004, p. 51).

Las aceptadas se resellaron con una estrella radiante y un fragmento cónico extraído de cada una como derecho de braceaje. Se conocen monedas reselladas y horadadas provenientes de Bolivia, Chile, Colombia, España, Estados Unidos, Guatemala, Honduras, México y Perú (Murillo, 2004, p. 200; Chacón-Hidalgo, 2008, p. 1132). Se estima que un total de 38.245 piezas fueron, así, habilitadas (Valerio-Garita, 2019, p. 173). La mayoría se fundieron en años posteriores y en la actualidad son muy escasas (Figura 3).

Figura 3. Casa de Moneda de San José. Ejemplos de monedas habilitadas en 1841. Resello de $6 \mathrm{~mm}$ sin leyendas, sobre monedas de varios países: círculo con una estrella radiante de seis puntas. Perforación cónica completa con diámetro aproximado de $9 \mathrm{~mm}$ para las monedas de ocho reales, de $8 \mathrm{~mm}$ para las de cuatro, de $7 \mathrm{~mm}$ para las de dos reales, de $5 \mathrm{~mm}$ para las de un real y de $4 \mathrm{~mm}$ para las de medio. A. Dos reales, Perú, 1828. B. Cuatro reales, Bolivia (Potosí), 1802. C. Un real, México, 1828. D. Un real, Guatemala, 1787.

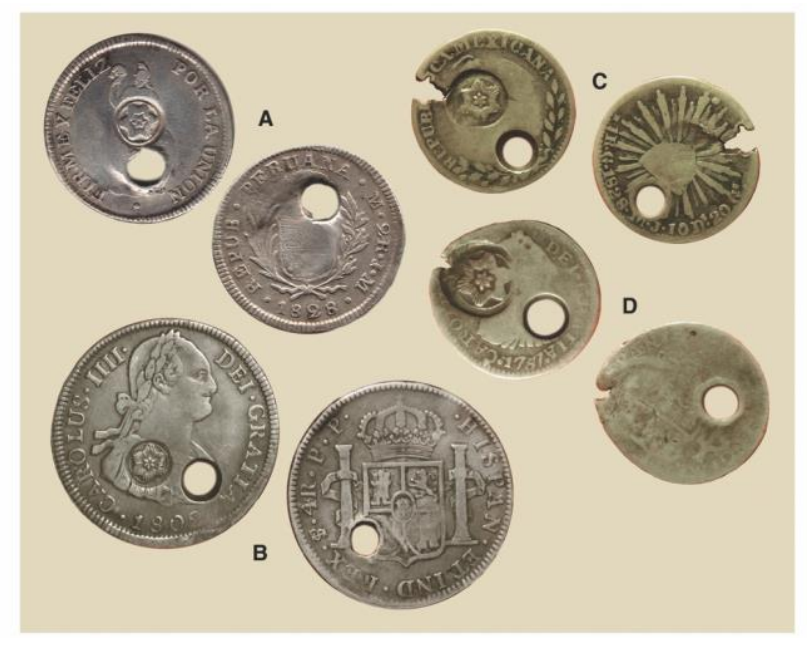

Fuente: Colección privada.

El resello de la estrella radiante representa al escudo de armas del Estado Libre de Costa Rica, que por su independencia brilla con luz propia (Vargas-Zamora y Murillo-Rivera, 2013, p. 19).

\section{El medio real de 1842 y el tabaco}

En la época colonial, además de los cultivos de cacao en las tierras bajas de Matina, se iniciaron los de tabaco (Nicotiana tabacum) en las tierras altas del Valle Central cerca de Cartago. No hay certeza de la fecha exacta, pero hay registro de que en 1638 se hizo una exportación de 10 quintales a Panamá. Otros informes de exportaciones durante el siglo siguiente incluyen un máximo, en 1766, de 1.031 quintales a Panamá y de 179 a Nicaragua. El transporte a lomo de mulas estaba a cargo de los arrieros (Acuña-Ortega, 1978, p. 284). 
Revista Herencia, Vol. 35 (1), enero-junio, 2022.

En 1781, el gobierno colonial se convierte en el organizador de la producción y monopoliza la compra y exportación del tabaco mediante la Factoría de Tabacos, que operó hasta mediados del siglo XIX. La Factoría fue una de las entidades financieras más importantes de finales del siglo XVIII y la primera mitad del XIX. La sede de la Factoría en la creciente ciudad de San José y la predominancia de cultivos a su alrededor fomenta el desarrollo de esta ciudad que luego sustituirá a Cartago como la capital. Para el año 1843 las rentas producidas por el monopolio representan el $36.8 \%$ de los 258.900 pesos del total de rentas (Araya-Pochet, 1981, p. 19).

Según (Villalobos-Rodríguez et al., 2000, p. 143) en 1840 mediante la aceptación de 2.000 petacas de tabaco como pago de la llamada deuda inglesa, que como parte de la República Federal le correspondía a Costa Rica y que había contraído en 1826, el jefe de Estado don Braulio Carrillo:

\footnotetext{
...honró el compromiso de pagar la deuda inglesa y con ello libró a Costa Rica de futuras expediciones punitivas, por parte de aquella potencia imperial. Él estaba interesado en establecer sólidos nexos comerciales con esa nación y necesitaba demostrar que el país, además de la seguridad interior que ofrecía, era capaz de cumplir sus compromisos internacionales
}

Aunque el cultivo del tabaco era una actividad importante desde tiempos coloniales, el pago de la deuda y la independencia de la Federación y de sus símbolos posiblemente motivaron que la imagen de una planta joven de tabaco fuera grabada en una moneda, el medio real de 1842, durante la administración de don Braulio. De estos medios reales o adarmes se acuñaron 7.200 monedas (Valerio-Garita, 2019, p. 183). Además del grabado de una planta de tabaco en el reverso, las monedas incluyen en el anverso el escudo del Estado Libre de Costa Rica (la estrella radiante de seis puntas) y al pie dos ramas entrecruzadas (Figura 4). 
Revista Herencia, Vol. 35 (1), enero-junio, 2022.

Figura 4. A. Medio real (1/ 2 R), 1842. Casa de Moneda. 18 mm, 1.5 g. Anverso: escudo del Estado de Costa Rica, estrella radiante de seis puntas. Bajo el escudo dos ramas entrelazadas, posiblemente una de mirto o de laurel europeos y otra de palma. En la orla, abreviado. Estado de Costa Rica. Reverso: en el centro, planta joven de tabaco (Nicotiana tabacum) y valor. En la orla, 10 D, 20 G (903 milésimas de plata).

M.M. (Miguel Mora) y fecha. B. Un escudo (1. E.), 1842. 19 mm, 3.0 g. Anverso: escudo del Estado de Costa Rica. En la orla, abreviado. Estado de Costa Rica. Bajo el escudo dos ramas entrelazadas como en el medio real. Reverso: en el centro, árbol del tipo federal y a cada lado del tronco, 1. y E. En la orla, 21 Q. (oro 21 quilates), M.M. (Miguel Mora), y fecha.

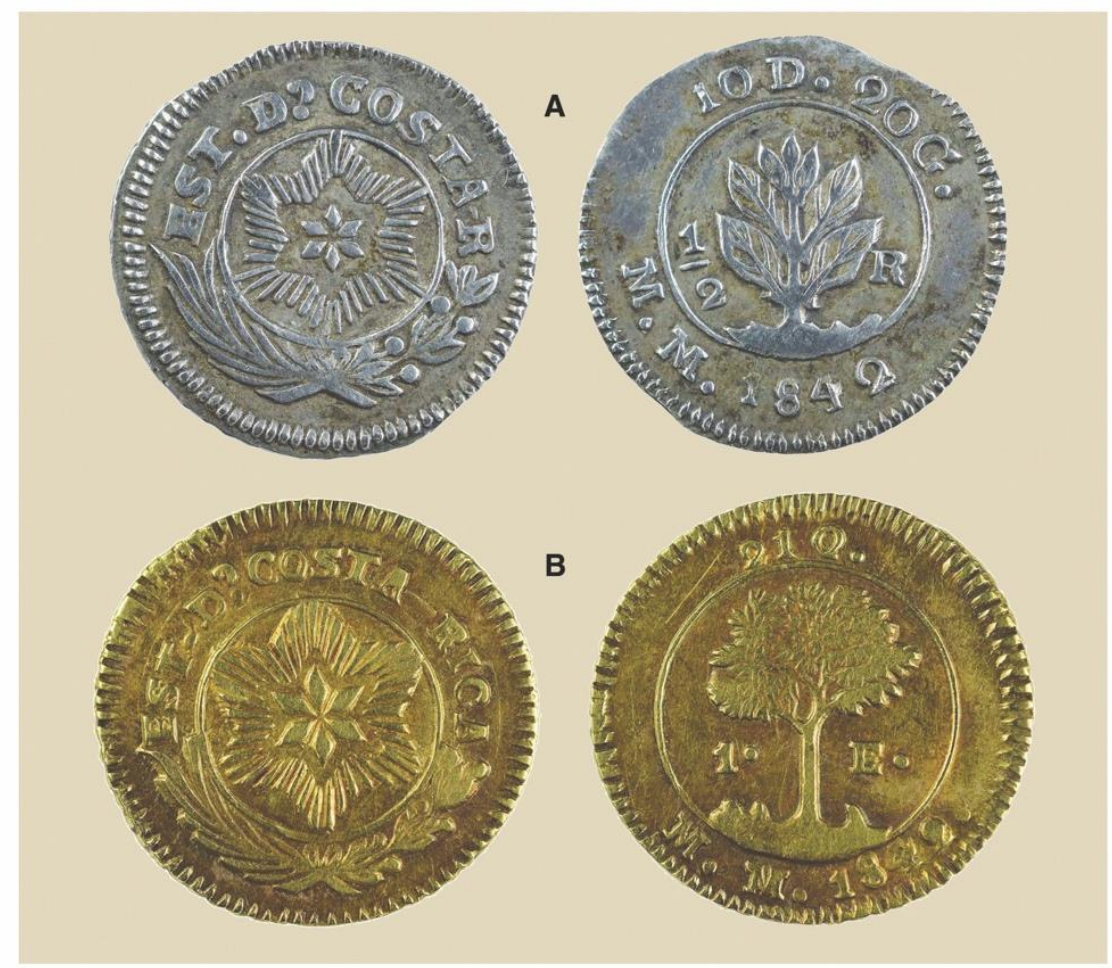

Fuente: Colección Museo BCCR.

En 1842, igualmente se realizó una emisión de monedas de oro de un escudo (Figura 4). En estas monedas se especificó grabar un arbusto de café; sin embargo, posiblemente por la falta de troqueles, se grabó el mismo árbol de las monedas federales. De esta moneda se estima se acuñaron un total de 5.077 piezas (Valerio-Garita, 2019, p. 183).

Vargas-Zamora y Gómez-Laurito $(2004,2006)$ argumentan que las ramas entrecruzadas podrían corresponder a una hoja (palma) de la palmera datilera y a una rama del mirto europeo (Myrtus communis), símbolo de paz. El mirto es parte del Escudo Nacional actual de Costa Rica y está grabado en el anverso de las monedas en circulación. Raymond (1937, p. 45) indica que estas ramas corresponden a una palma y al laurel europeo (Laurus nobilis), símbolo de victoria. Desde tiempos antiguos se elaboran coronas con ramas de tres especies de árboles europeos: el mirto, el laurel, y el olivo (Olea europaea). Las tres poseen hojas alargadas de borde liso y frutos pedunculados, por lo que es difícil identificar la especie con base en las figuras en las monedas. Además, como en el caso de la ceiba y la palmera, los decretos respectivos no aportan datos sobre las especies de plantas grabadas. 
Revista Herencia, Vol. 35 (1), enero-junio, 2022.

\section{El resello de pesetas españolas (1845) y la figura femenina}

Las monedas de medio real con la figura del tabaco, así como otras de plata emitidas por la Casa de Moneda desde 1831, contienen 903 milésimas (10 Dineros, 20 Granos) de plata. En este contexto muchas de las monedas extranjeras en circulación tenían un contenido de plata inferior al legal en Costa Rica y esto se toleraba, dentro de ciertos límites, por necesidad ante la escasez de circulante. Entre las monedas extranjeras había una cantidad importante de pesetas españolas de valor nominal de dos reales y algunas de cuatro reales de vellón. Por su menor contenido de plata (812 y 833 milésimas) las pesetas de dos reales de busto valdrían localmente cerca de 1.8 reales. El 13 de noviembre de 1845, el jefe de Estado, don José Rafael Gallegos, emitió el decreto LIII (Gobierno de Costa Rica, 1862) en el cual se formalizaron los valores por los que serían aceptadas las monedas extranjeras. En el caso particular de las pesetas, se prevé su amortización posterior:

Art. 1. Las pesetas españolas a excepción de las de Isabel II continuarán corriendo a razón de dos reales cada una, es decir cuatro por un peso.

Art. 2. Los tenedores de pesetas de dicha clase, las presentarán a la casa de moneda dentro del preciso término de sesenta días contados desde esta fecha, para que sean reconocidas y habilitadas mediante una marca especial que el gobierno dispondrá al efecto...

Art. 4. El Gobierno cuidará de amortizar, tan luego como lo permitan las circunstancias del erario, la porción de pesetas españolas que hubiesen sido habilitadas conforme al art. 2, pagándolas por el mismo valor con que se permiten circular...

Con estos resellos, la Casa de Moneda obtuvo una ganancia al autorizar pesetas de menor valor intrínseco que el nominal (moneda fiduciaria) y no se veía compelida a acuñar monedas de dos reales con el contenido de plata de 903 milésimas. Al mismo tiempo, se obligó al usuario a aceptar las pesetas bajo pena de multa. Se conocen ejemplares de pesetas reselladas que cubren el periodo desde 1709 hasta 1833, fin del reinado de Fernando VII. La mayoría corresponden a monedas emitidas por las cecas de Madrid y Sevilla y existen raros ejemplares de las cecas de Cádiz y Valencia. Curiosamente, también se resellaron unos pocos ejemplares de monedas de dos reales de Potosí (Chacón-Hidalgo, 2008, p. 1136; Vargas-Zamora et al., 2018, p. 21).

El resello doble de $13 \mathrm{~mm}$ de diámetro consistió en el busto de una joven mirando a la izquierda y con el pelo recogido hacia atrás; sobre ella la leyenda Costa Rica, y bajo el busto, 2. $R$. (Dos reales). En la otra cara de la moneda, un árbol similar al grabado hasta la fecha y la leyenda abreviada, Habilitada por el Gobierno (Figura 5). 
Revista Herencia, Vol. 35 (1), enero-junio, 2022.

Figura 5. Casa de Moneda de San José. Resellos de 1845. Resello doble de 13 mm de diámetro sobre el anverso y reverso de pesetas españolas. Anverso: Busto de una joven mirando a la izquierda y con el pelo recogido hacia atrás. En la orla la leyenda Costa Rica y 2. R. Reverso: árbol de tronco recto y copa globular, símbolo de libertad. En la orla la leyenda abreviada Habilitada por el Gobierno. A. Sevilla. Felipe V, 1737. 5.6 g, 26 mm B. Sevilla, Carlos III, 1774, 5.3 g, 26.5 mm C. Madrid, Carlos IIII, 1800. 5.5 g, 26 mm D. Madrid, José Napoleón, 1811, 4 reales. 5.5 g, 26 mm E. Sevilla, Fernando Séptimo, 1828, con resello de retículo de Cuba (1841). 5.8 g, 26 mm F. Sevilla, Fernando Séptimo, 1833. 5.7 g. 25.5 mm Última fecha con resellos.

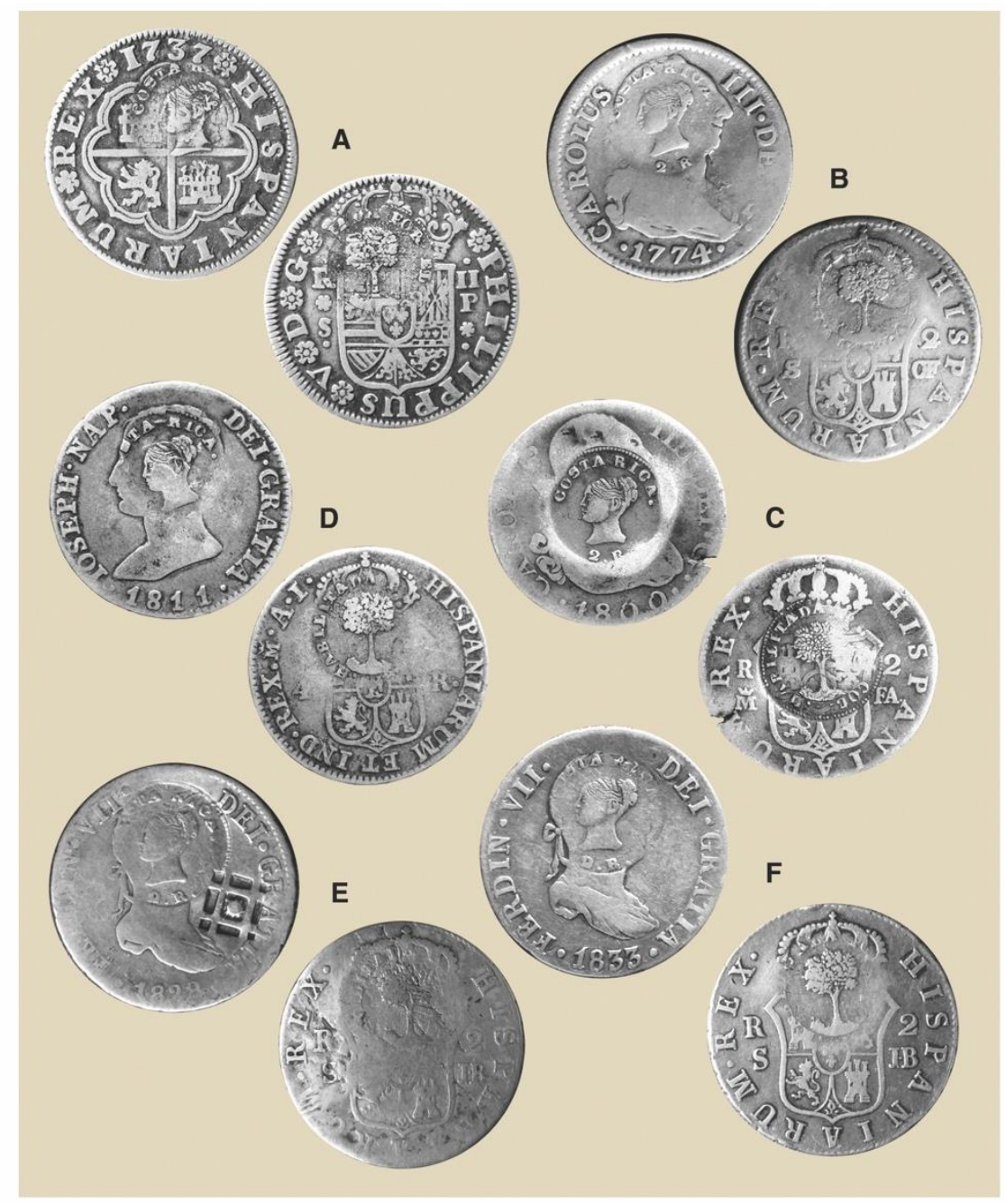

Fuente: Colección privada.

La figura femenina en el resello de las pesetas, la primera en una moneda de Costa Rica, posiblemente sea la representación simbólica de la joven nación. Se ha especulado sobre la similitud de la imagen con la de la joven reina Victoria de Inglaterra grabada en monedas inglesas de esa época (Chacón-Hidalgo, 2008, p. 1138). Sin embargo, no se ha localizado documentación que apoye o descarte algún vínculo (Vargas-Zamora et al., 2018). Tampoco se ha localizado información que permita estimar el número de piezas habilitadas. Algunas pesetas habían sido reselladas previamente en Cuba en 1841 (Figura 5). 
Revista Herencia, Vol. 35 (1), enero-junio, 2022.

En 1845 y para suplir la demanda de monedas de valor inferior al medio real se acuñó, por única vez, monedas de plata de un cuarto de real, o cuartillo, con diámetro de $12 \mathrm{~mm}$ y peso de $0.85 \mathrm{~g}$. Su pequeño diámetro solo permitió que se grabara el árbol federal y a los costados del tronco C.R. (Costa Rica) y 1/4. En el anverso, un sol naciente detrás de tres montañas y la fecha (Gurdián-Montealegre, 1996, p. 61).

\section{El resello de las macuquinas coloniales (1846)}

Cabe considerar que, gracias a las acuñaciones de la Casa de Moneda y a la habilitación de monedas extranjeras de cordoncillo en 1841 y 1845, la mayor parte del dinero circulante en Costa Rica hacia mediados del siglo XIX estaba integrado por moneda cordonaria; pero este no fue el caso, pues circulaba gran cantidad de monedas sin cordón conocidas como macuquinas.

Aproximadamente, hacia 1600 (Soley-Güell, 1975, p. 28), se inició la introducción de macuquinas en el país. Sin embargo, la gran mayoría de las macuquinas en uso en Costa Rica fueron acuñadas en el siglo XVIII (las últimas en 1773), y provenían de las cecas de Guatemala, Lima y Potosí. Uno de los problemas de las macuquinas fue que al no poseer cordón era fácil robarles valor al cortar fragmentos de los bordes. Por ejemplo, las monedas ilustradas en la figura 6 pesan menos que el valor teórico (según la normativa colonial de 1728, los pesos son: $27.06 \mathrm{~g}$ para las de ocho reales, $13.53 \mathrm{~g}$ para las de cuatro, $6.76 \mathrm{~g}$ para las de dos y $3.38 \mathrm{~g}$ para las de un real). Otra característica de las macuquinas es que, por haber sido hechas a mano, cada una es una pieza única en forma y detalles (Sedwick y Sedwick, 2007, p. 9). Burzio (1958: 11) define la macuquina, como:

la moneda colonial hispanoamericana, de plata u oro, batida en cospeles irregulares, sin cordoncillo, de bordes recortados, espesor y módulo variable y de tosca acuñación, que con el nombre de corriente circuló en América con un valor menor respecto a la de cordoncillo de los tipos columnario y de busto, llamada fuerte.

A mediados del siglo XIX la frecuente aparición de macuquinas falsas, o cercenadas a tal grado que su valor nominal no correspondía con el intrínseco, hizo necesario que el jefe de Estado, don José María Alfaro, emitiera el decreto CII del 15 de octubre de 1846 (VargasZamora et al., 2021), en el que se resalta:

Considerando: 1. Que es muy frecuente y considerable la introducción que se hace al Estado de moneda falsa macuquina, cuya facilidad de contrahacer por lo sencillo y grosero de sus armas, no permite se distinga de la legítima en los actos del tráfico. 2. Que por esta causa el pueblo repugna generalmente toda moneda cortadilla cuando de otro parte no circula en el país más que una pequeña suma de cordón.

Decreta. Art. 1. Desde el 1 de noviembre próximo, no circulará en el Estado ninguna moneda macuquina cualquiera que sea su valor, sin que esté sellada, como en este decreto se previene.

Sobre la mayor abundancia de las macuquinas con respecto a las de cordón, el decreto es claro al indicar, ...cuando de otra parte no circula en el país más que una pequeña suma de cordón. 
Revista Herencia, Vol. 35 (1), enero-junio, 2022.

A pesar del decreto, las macuquinas de medio real no fueron reselladas, posiblemente por su pequeño tamaño. El resello se aplicó a las de uno, dos, cuatro y ocho reales. Se utilizó como resello en el anverso la impresión del troquel de $14 \mathrm{~mm}$ del medio escudo de oro de 1846. En el reverso se grabó un círculo de $14 \mathrm{~mm}$ con el árbol copado, símbolo de libertad, en el centro y a los costados del tronco 1 y R, o 2 y R, según el valor de la moneda. A las de cuatro reales se les grabó los círculos correspondientes a $1 \mathrm{R}$ y además un 4 dentro de un cuadrado de esquinas redondeadas; asimismo, a las de ocho reales se les grabó los correspondientes a $2 \mathrm{R}$ y un 8 dentro de un círculo (Figura 6).

Figura 6. Casa de Moneda de San José. Resellos de 1846 sobre monedas macuquinas coloniales. Anverso: impresión del troquel de $14 \mathrm{~mm}$ del medio escudo de oro de 1846. Leyenda abreviada República del Centro de América en medio de dos círculos concéntricos. Reverso: círculo de $14 \mathrm{~mm}$, al centro árbol de tronco recto y copa globular, símbolo de libertad, flanqueado por $1 \mathrm{R}$ o $2 \mathrm{R}$ según el valor de la moneda. Leyenda

Habilitada en Costa Rica. J.B. (Juan Barth). En las de cuatro reales, $1 \mathrm{R}$ y un 4 adicional dentro de un cuadrado de bordes redondeados. En las de ocho reales, $2 \mathrm{R}$ y un 8 adicional dentro de un círculo. A. Un real, Potosí, 2.78 g. B. Dos reales, ¿Potosí ?, ejemplar raro con fecha original (1758) legible, 6.74 g. C. Cuatro reales, Guatemala, 1752, 12. 98 g. D. Ocho reales, Guatemala, 1753, 23 g. Colección Museo BCCR. E. Ocho reales, Lima (L), 1701. 26.65 g. A, B, C. E.

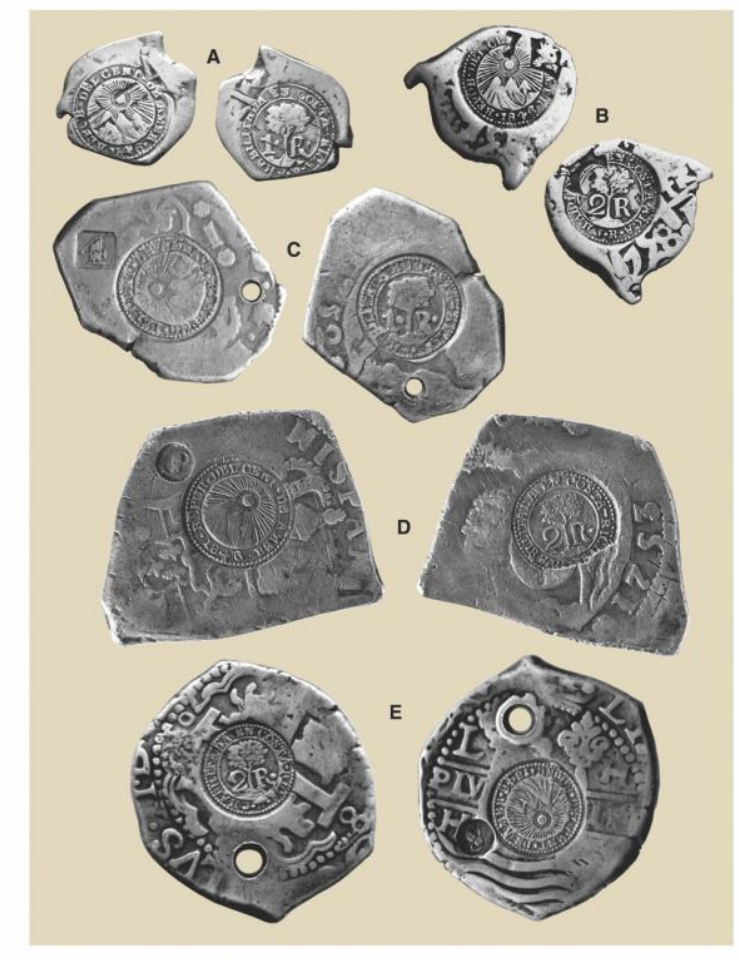

Fuente: Colección privada.

No se conocen datos de cuántas monedas fueron así reselladas. La circulación de las macuquinas se prohibió en 1849 y se sustituyeron por las nuevas monedas de la República (Vargas-Zamora et al., 2021). Los resellos de 1846 fueron igualmente aplicados en raras ocasiones sobre monedas con canto de cordoncillo. Entre los escasos ejemplares hay monedas reselladas de Bolivia, España, Estados Unidos de América, Francia, Inglaterra, México y Perú (Murillo, 2004, p. 201). 
Revista Herencia, Vol. 35 (1), enero-junio, 2022.

\section{Las mariquitas de un real (1847-1850) y el auge del cultivo del café}

El café (Coffea arabica) fue introducido en Costa Rica posiblemente en 1791, cuando el comerciante Agustín de Gana le envió por barco desde Panamá dos arrobas de café al gobernador colonial de Costa Rica, don José Vásquez y Téllez. Las primeras plantas crecieron en jardines de casas de Cartago. Correspondió al gobernador don Tomás de Acosta, y al sacerdote Félix Velarde, el expandir el cultivo fuera de Cartago. En 1804, don Tomás declaró libres de impuestos las nuevas plantaciones de añil, algodón, cacao y café. El 12 de octubre de 1820 se exportó por barco a Panamá un quintal de café; de ahí en adelante el cultivo toma auge, en parte por la política agrícola de don Braulio Carrillo (Sáenz-Maroto, 1970, p. 208-218). Las bebidas tradicionales (chocolate a base de cacao y aguadulce a base de caña de azúcar) poco a poco cedieron espacio al café. Para mediados del siglo XIX el café había llegado a ser el principal producto del país y sus plantaciones (cafetales) ocupaban gran parte de los alrededores de la ciudad de San José y se expandían hacia Heredia y Alajuela.

El café era transportado por el camino, mejorado para ese fin, al puerto de Puntarenas, Golfo de Nicoya, a bordo de carretas tiradas por bueyes y conducidas por boyeros, algunos cuyos ancestros habían sido arrieros. En 1839 el buque Halcyon (138 toneladas de desplazamiento) del capitán inglés William Le Lacheur embarca en Puntarenas 2.397 quintales de café con destino a Londres. Estos viajes demoraban alrededor de 100 días vía el Cabo de Hornos, con escala frecuente en Valparaíso, Chile (León-Sáenz, 2002).

Luego gran parte del transporte entre 1843 y 1852 estuvo por cuenta del Monarch (234 toneladas) del mismo capitán. El envío de café a Londres continuaría hasta 1886 a cargo principalmente de esta empresa, con nuevos y veloces veleros de hasta 653 toneladas (LeónSáenz, 2002). Según León-Sáenz (2002, p. 67) en 1843 las exportaciones de Costa Rica en miles de pesos se distribuían principalmente en: maderas (0.5), cochinilla/añil (1.4), cueros (2.7), dulce de caña de azúcar (5.1), tabaco (31.5) y café (201.5).

La exportación de café a Inglaterra traía de regreso al país gran cantidad de productos europeos, como alimentos enlatados, licores, aceites, muebles, porcelana, herramientas, ropa y telas. Esto trajo como consecuencia un cambio radical en la vida doméstica de los cafetaleros y otros ciudadanos con poder adquisitivo, quienes podían obtener bienes que antes del café estaban lejos de su alcance (Vega-Jiménez, 1991).

El viajero escocés Robert Dunlop, quien visitó Costa Rica en 1844, aporta datos en su libro Travels in Central America publicado en 1847 y traducido por Fernández-Guardia (2002, p. 91), sobre el costo de producción del grano, el costo diario de la mano de obra y la escasez de esta:

...El costo total de la producción de un quintal de café (101 1/3 libras británicas), inclusive la
asistencia de la finca, la limpieza y poda de las plantas, la recolección y preparación de las
bayas, se calcula, al precio actual de la mano de obra (dos reales o alrededor de un chelín al
día) en dos y medio dólares (equivalentes a diez chelines), pero los peones apenas alcanzan
ahora para el trabajo de todas las fincas existentes...
... La cosecha total del año 1846 alcanzó unas 3.000 toneladas y se tiene la esperanza de que la
de 1847 pase de 4.000, continuando probablemente alrededor de esa cifra mientras vaya

ISSN: 1659-0066 
Revista Herencia, Vol. 35 (1), enero-junio, 2022.

creciendo la población, porque como se ha dicho ya los jornaleros apenas bastan para los cultivos existentes. Siendo así que el precio actual es por término medio de 50 chelines el quintal en el mercado inglés, la producción resulta muy considerable para un paisecito americano que apenas tiene 80.000 habitantes...

En el contexto de la escasez de mano de obra mencionada por Dunlop, así como el de la cantidad de usuarios de monedas y la magnitud de la producción cafetalera, cabe recordar que la población de Costa Rica en 1844 era realmente de 93.871 habitantes (Thiel, 1902, p. $30)$.

En el ambiente político, el 7 de junio de 1846 se introducen reformas constitucionales y el 21 de enero de 1847 se aprueba una nueva constitución. El 7 de marzo, día de jura de la constitución, se dispuso que en las cabeceras de los cinco departamentos del país los sacerdotes lanzaran al pueblo el equivalente de 275 pesos (2.200 monedas de un real) de un total cercano a 5.500 acuñadas para el evento. El lanzamiento de monedas era un recuerdo de la tradición colonial de manifestar lealtad a un nuevo monarca (Vargas-Zamora y Chacón-Hidalgo, 2016), como ocurrió en Cartago el 15 de enero 1809 para la jura a Fernando VII, según lo relata Jiménez (1902, p. 89):

...volvieron a la Plaza Mayor, en la que estaba preparado un decente tablado para la Jura, subieron a él el Gobernador y los reyes de armas, los cuales dieron las voces acostumbradas, y el Gobernador profirió la Jura en la forma de estilo, arrojando al pueblo muchos puñados de dinero, por falta de moneda con la Real Efigie...

La moneda de un real de 1847 conmemora las reformas introducidas en 1846, y como tal es la primera moneda conmemorativa emitida en Costa Rica. Al ser de curso legal mitigó un poco la escasez de circulante de esa denominación. La moneda tiene en su anverso un cafeto con frutos. El grabado de un árbol de café en la moneda está indicado en el decreto emitido el 10 de febrero de 1847 (Murillo, 2004 p. 64). En el reverso, también según lo indica el decreto, se grabó la imagen de una joven india; esta es la segunda imagen femenina en monedas de Costa Rica (Figura 7). Sin embargo, el decreto no aporta información sobre los motivos de la escogencia de esos símbolos. 
Revista Herencia, Vol. 35 (1), enero-junio, 2022.

Figura 7. Un real, Mariquitas. Casa de Moneda, San José. A. Un real 1847. 20 mm 2.8 g. Primera moneda conmemorativa de Costa Rica. Anverso: centro con arbusto de café (Coffea arabica), con frutos. A los lados del tronco 1. R. En la orla, abreviado, Reformas Proclamadas el 7 de junio de 1846. Reverso: busto de una joven india con los hombros descubiertos, brazos cruzados, sosteniendo el traje entre los dedos de la mano derecha. En la orla, abreviado, A la Constitución de 21 de enero de 1847, Costa Rica (C.R.), Juan Barth (J. B.). Plata 903 milésimas. B. Un real, 1849, $20 \mathrm{~mm} 2.7$ g. Anverso: centro con arbusto de café con frutos. En la orla, por primera vez en monedas del país, República de Costa Rica (fundada en 1848). J. B. (Juan Barth), 9.D. (750 milésimas de plata).

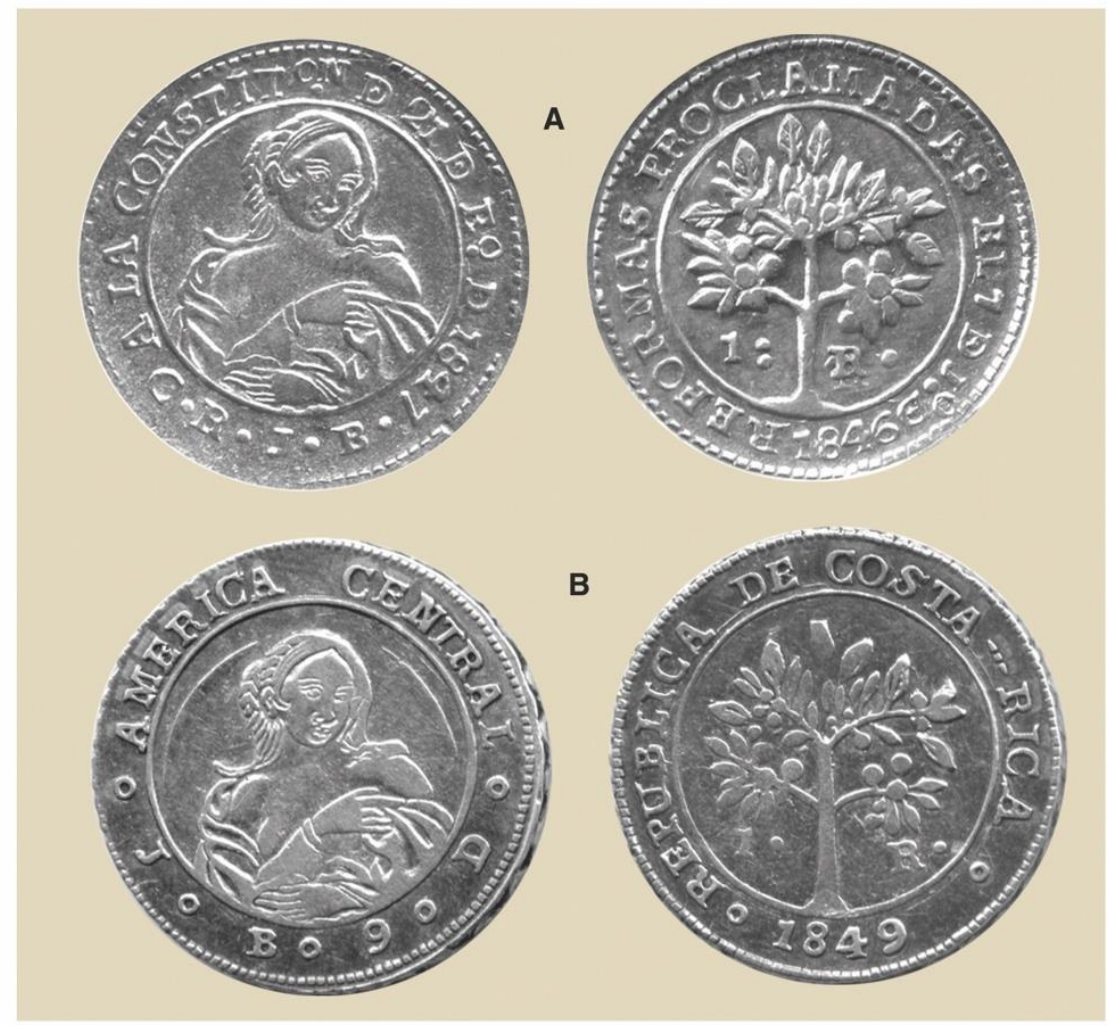

Fuente: Colección privada.

Es posible que, por haber sido lanzadas al pueblo por sacerdotes, y por la similitud de la imagen de la india con representaciones marianas, las monedas recibieron el sobrenombre de mariquitas. Otra explicación es que el sobrenombre tiene su origen en doña María Peralta y Echeverría (doña Mariquita), esposa de don Manuel José Carazo, el ministro de hacienda y guerra, quienes regentaban una tienda de variedades en la Calle del Carmen de San José (Fernández-Guardia 2002, p 145). En 1849 y 1850 se emitieron monedas similares en las que, por primera vez, aparece grabada la leyenda República de Costa Rica (fundada en 1848). Debido a la escasez de metal plata las emisiones de 1849 y 1850 fueron hechas sobre monedas coloniales (Vargas-Zamora y Chacón-Hidalgo, 2016, p. 59). En la figura 7 B se observan restos de la moneda colonial como líneas curvas a los costados de la cabeza de la india. 
Revista Herencia, Vol. 35 (1), enero-junio, 2022.

\section{La escasez de reales y los boletos de café}

El auge del cultivo del café, y el aumento de las plantaciones con la consiguiente demanda de contratación de jornaleros y cosechadores, incrementaron la escasez de monedas de medio, uno, y dos reales, ya de por sí insuficientes, para el pago diario de los trabajadores. Para mitigar este problema los caficultores (y las caficultoras) introdujeron, a mediados de la década de 1840, el uso de moneda privada, los boletos de café, que se entregaban como pago temporal al trabajador al final de la jornada, o por cada unidad de volumen de café recolectado.

Los boletos eran canjeados el fin de semana, en la casa u oficina de la plantación, por el total acumulado que podía ser pagado entonces con monedas de mayor denominación como las de ocho reales o los escudos de oro. Esto, además de facilitar la contabilidad, no requería de disponer de tanta moneda de baja denominación y era más seguro y práctico que llevar y entregar efectivo diariamente en la plantación. Los boletos fueron acuñados generalmente en bronce, en valores de medio y un real, o en unidad de volumen como un canasto (Figura 8) y eran válidos únicamente en la plantación para la que se laboraba. Los boletos también tenían las funciones de servir de control de la fuerza laboral y de retener temporalmente el efectivo (Vargas-Zamora, 2020). Por estas y otras razones el éxito de este medio de pago continuó y hoy todavía se utilizan en algunos grandes cafetales

Figura 8. Monedas privadas (boletos de café) de mediados del siglo XIX para el pago temporal de jornaleros y cosechadores en las plantaciones de café (cafetales). Bronce. A. Juan Rafael Mora (1814-1860),

Hacienda Franfort. Monograma JRM. Medio real. 13 mm B. José E. Echandi (1814-1866). Hacienda Esperanza. Cafeto. Medio real. $19 \mathrm{~mm}$ C. Pedro García (1816-1893). Medio real. $21 \mathrm{~mm}$ D. Gerónima Fernández (1788-1858), 21 mm, Un canasto. E. Francisco N. Millet (1826-1910). Hacienda La Louisa Paras. Un real, $13 \mathrm{~mm}$

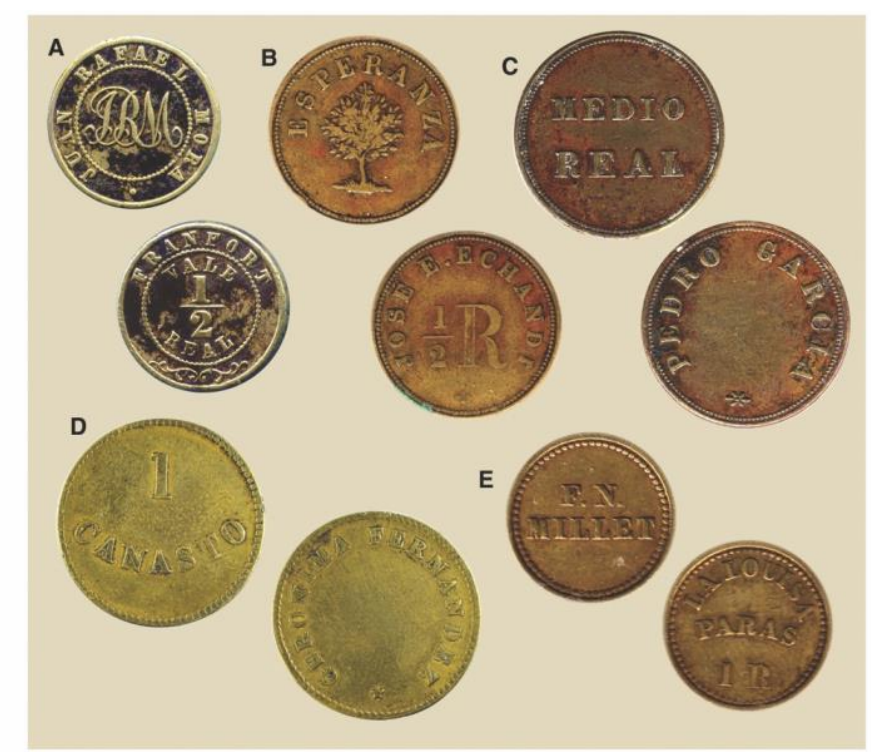

Fuente: A, B, C, E. Colección JVZ. D. Colección Museo BCCR. 
Revista Herencia, Vol. 35 (1), enero-junio, 2022.

\section{Otras emisiones de reales y el resello del león pasante (1849)}

Después de las emisiones de moneda de medio real en 1831 y 1842 , y por la mayor necesidad de esta moneda de baja denominación, se hicieron emisiones de adarmes en 1843, $1845,1846,1847,1848$ y 1849 . Se acuñaron monedas de un real en 1848 y 1849 y de dos reales en 1849. Como ya se ha anotado, no obstante que Costa Rica no era miembro de la Federación desde 1838, la falta de troqueles hizo que ante la urgencia de circulante se utilizaran los disponibles que contenían el árbol símbolo de libertad, así como los símbolos federales en el anverso de esas monedas. La declaración de Costa Rica como República en 1848 hizo necesario obliterar esos símbolos federales con la aplicación de un resello.

Mediante decreto del 22 de noviembre de 1849 se autoriza resellar sobre el árbol en el reverso las monedas de medio, uno, y dos reales con un círculo de $5 \mathrm{~mm}$ de diámetro que contiene un león pasante y en la orla la leyenda Habilitada por el Gobierno. De la misma manera fue resellada la moneda de medio real de tabaco de 1842, que no tenía grabados símbolos federales, pero sí los del antiguo Estado. La aplicación fuerte del resello dejó su impronta en el anverso, con lo cual se obliteraban parcialmente los símbolos en esa cara de las monedas (Figura 9).

Figura 9. Resello del león pasante de $5 \mathrm{~mm}$ de diámetro sobre el reverso de las monedas de medio, uno y dos reales para obliterar los símbolos federales: A. Medio real, 1831, 12 mm, 1.7 g. 10 D. 20 G (903 milésimas de plata). B. Medio real, 1842, 18 mm, 1.5 g. (Ver Fig. 4 A). C. Un real (1. R.), 1849, 20 mm, 3.4 g. J.B., 9. D. (750 milésimas de plata). D. Dos reales (2. R.), 1849, 25 mm 6.7 g, C.R. (Costa Rica), J.B. (Juan Barth), 9. D. (750 milésimas). E. Detalle del resello. En la orla Habilitada por el Gobierno.

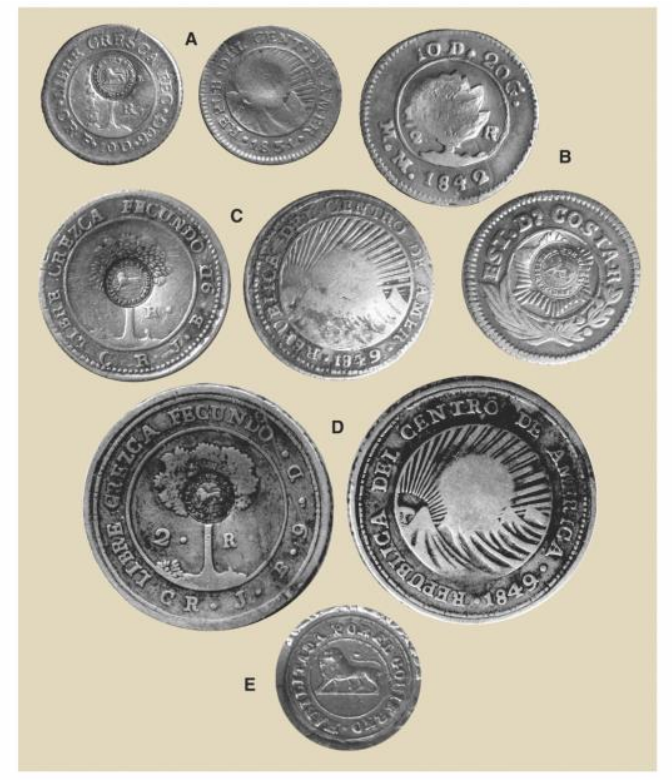

Fuente: Colección privada.

No hay información sobre el por qué fue grabado un león pasante, aunque se conoce que los punzones con el resello fueron elaborados en Inglaterra (Murillo, 2004, p. 80), donde ese símbolo era común. 
Revista Herencia, Vol. 35 (1), enero-junio, 2022.

\section{El resello de los peniques y chelines ingleses (1850)}

El comercio con Europa a través del puerto de Puntarenas tomó auge en la década de 1840. Buques de varias naciones europeas traían insumos para la venta y regresaban cargados de café y otros productos. El aviso publicado en el periódico semanario Mentor Costarricense en su edición No. 86, del 12 de abril de 1845, es interesante en el contexto del intercambio de café por abarrotes:

MARINA Punta-Arenas. Entrada de buques. Abril 4. La Barca Española "Resolución" del porte de doscientas ochenta toneladas, procedente de Valparaíso, Callao i Paita, su Capitán Señor Salvador Fábrega, su cargamento abarrotes, consignada a los Señores Espinach y Giral. Compra café i cambia también por su cargamento.

Gran parte del trasiego de café y productos estaba a cargo de los buques del capitán Le Lacheur, mencionado antes, que traían al país insumos diversos como pago por la venta del café, aunque parte del pago se hacía en moneda inglesa. En el Mentor Costarricense, en su edición No. 85, de fecha 2 de abril de 1845, se indica:

MARINA. Puntarenas. Entrada de buques. Marzo 29. La barca inglesa Monarch, de 224 toneladas procedente de Valparaíso en lastre i con 36.700 pesos en dinero para pagar café comprado ya. Su capitán Señor Tomas Sepes i consignada al Capitán Le Cheur.

Es posible que ese embarque de dinero a bordo del Monarch estuviera integrado en gran parte por piezas inglesas de varias denominaciones. En el Mentor Costarricense, edición No. 91, del 24 de mayo de 1845, se menciona la salida de esa misma nave cargada con café:

MARITIMA PUNTA-ARENAS. Salida de buques. Mayo 9. Barca inglesa MONARCA para Europa. Su capitán el Señor Tomás La Page con 14 hombres. Su cargamento 5599 quintales de café $i 4$ quintales zarza de la pertenencia de los Señores Brealy i Le Lacheur

La circulación de monedas inglesas era común en Costa Rica asociado a ese creciente comercio. Por tal motivo, el 27 de septiembre de 1848 se emite el decreto (Murillo, 2004, p. 66), que indica:

El poder legislativo decreta en el artículo único que la moneda inglesa conocida con el nombre de Libra esterlina circulará en el país por el valor de cinco pesos. José María Castro.

En 1850, la escasez de moneda de plata continuaba siendo un problema especialmente para el pago de los trabajadores y las compras diarias de los hogares. Entre las monedas inglesas que circulaban estaban los peniques (six pence) y los chelines (one shilling). Según Dunlop, mencionado antes, con un chelín se pagaba la jornada diaria de un trabajador en un cafetal. El 17 de enero de 1850 se emitió el decreto, mediante el cual se ordena resellar los peniques y los chelines para autorizar su circulación por valor de uno y dos reales, respectivamente. Ambas monedas tienen un contenido de plata más alto (925) que el de las monedas de la Casa de Moneda (903), por lo que al autorizar su circulación la Casa obtenía una ganancia adicional. El resello consistió (Figura 10) en un círculo de $6 \mathrm{~mm}$ de diámetro, con un león pasante en el centro y la leyenda Habilitada por el Gobierno en la orla (GurdiánMontealegre, 1996, p. 68).

ISSN: 1659-0066 
Revista Herencia, Vol. 35 (1), enero-junio, 2022.

Figura 10. Resello de $6 \mathrm{~mm}$ de diámetro del león pasante sobre monedas inglesas, 1850. Se conocen monedas reselladas fechadas entre 1816 y 1850: A. Six pence (penique), 1834. 3.0 g. Rey Guillermo IV. Habilitado para circular por valor de un real. 925 milésimas de plata. B. One shilling (chelín), 1826, Rey Jorge IV. 5.6 g. C. One shilling (chelín), 1844. 5.6 g. Reina Victoria. Habilitados para circular por valor de dos reales. 925 milésimas.

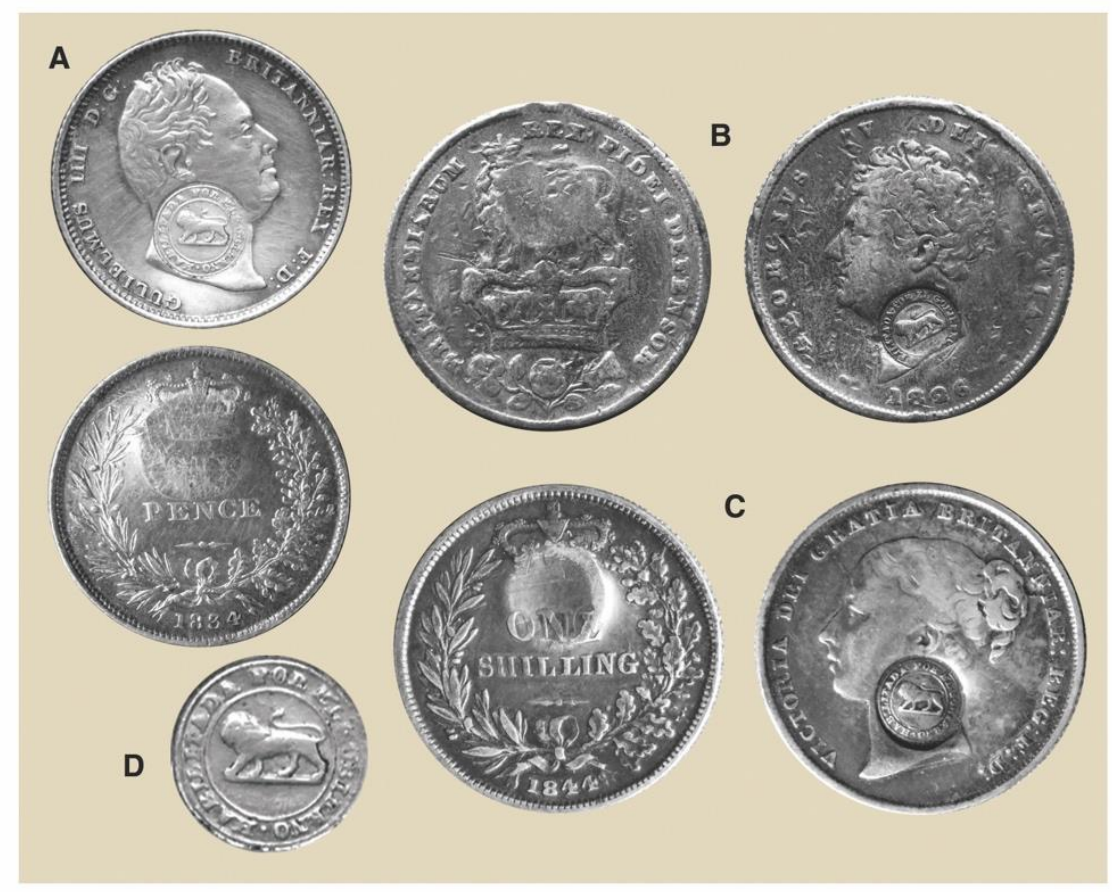

Fuente: Colección privada.

\section{Las monedas de la República de Costa Rica}

El 31 de agosto de 1848 durante el gobierno del Dr. José María Castro se proclamó a Costa Rica como República soberana e independiente y el Dr. Castro fue elegido como su primer presidente. Correspondió entonces definir las características de las nuevas monedas y el 29 de setiembre de 1848, se decretó (Murillo, 2004, p. 70):

...Artículo 6. La moneda de la República se sellará en el anverso con el escudo descrito en el Articulo 3 debiendo ser en la orla de dicha moneda donde ha de estar la leyenda República de Costa Rica junto con la fecha del año respectivo. Por el reverso la de oro contendrá en el centro la figura de una india en pie, armada de arcos carcaj y flechas, y descansando sobre el brazo izquierdo apoyada en un pedestal que contenga la inscripción 15 de setiembre de 1821. La de plata contendrá un árbol de encina sobre un terreno figurado y la orla del reverso de todas las monedas, sean de oro o plata tendrán este título América Central junto con el nombre del ensayador en iniciales, el valor correspondiente de la pieza y su respectiva ley.

\section{Las monedas de la india en pie}

Para la acuñación de las nuevas monedas de la República, los troqueles fueron encargados a la casa grabadora Wyon, de Inglaterra (Murillo, 2005, p. 78). En el anverso de la moneda de oro el escudo de armas fue colocado sin los trofeos de guerra dentro de un marco y en la 
Revista Herencia, Vol. 35 (1), enero-junio, 2022.

base dos ramas forman una media corona, posiblemente de mirto (Vargas-Zamora, 2008, p. 93). Sin embargo, Raymond (1937, p. 46) atribuye las ramas al laurel europeo.

En estas monedas de oro la representación de una india en pie, según el decreto, armada con su arco, flechas, y adornada con corona, se asemeja más a una escultura grecorromana de la diosa Artemisa o Diana la cazadora (Vargas-Zamora, 2008, p. 97). La figura de una india armada y desnuda se utilizaba desde inicios del siglo XVI como representación de América, el Nuevo Continente, que alude a una tierra feminizada disponible para la exploración y posesión masculina (Detsi-Diamanti, 2006, p. 62). La figura de la india en la moneda costarricense posiblemente es símbolo de libertad, tal como había sido el árbol en las monedas federativas. Según lo indica Konig (2014, p. 12):

\footnotetext{
...Esta representación simbólica de la libertad en el cuerpo de una amazona americana con armas y corona prestó un nuevo sentido a la figura de la india, que ya había aparecido en cuadros alegóricos del arte europeo como la América personificada. Desde el descubrimiento de un nuevo mundo, en 1492, resurgió la representación alegórica de los continentes por medio de figuras femeninas. Por eso, la india desnuda, muchas veces con armas y signos de canibalismo, tal como la había descrito sobre todo Amerigo Vespucci en su carta Novus Mundus, de 1502, se convirtió en el símbolo de América.
}

No obstante, es posible que otra intención fuese la de reconocer la contribución histórica de los pobladores originales, así como en este caso conmemorar, por primera vez en una moneda, la fecha - 15 de setiembre de 1821- grabada en el pedestal (Figura 11 A, B, D). La india en pie es la tercera imagen femenina en monedas de Costa Rica del siglo XIX. 
Revista Herencia, Vol. 35 (1), enero-junio, 2022.

Figura 11. Monedas de oro de la india en pie. Anversos: Escudo de armas sin armas y al pie media corona. En la orla República de Costa Rica y fecha. Reversos: Figura de una india con arco, flechas corona y pelo recogido hacia atrás, apoyada sobre pedestal donde se lee 15 DE SET. DE 1821. En la orla, América

Central, $21 \mathrm{Q}^{\mathrm{s}}$, ensayador y valor. A. Medio escudo (1 Peso), 1855, $1.7 \mathrm{~g}, 14 \mathrm{~mm}$ J. B. (Juan Barth). Nótese la india sin censura en sus pechos. B. Dos escudos (2 E) o cuarta, 1855, $6.7 \mathrm{~g}, 23 \mathrm{~mm} 21$ Qs., G.W.

(Guillermo Witting). Nótese la india censurada mediante el aplastado de los pechos. C. Un thaler, Bavaria, 1835 , plata $833,28.0 \mathrm{~g}, 38 \mathrm{~mm}$, con una figura femenina vestida de cuerpo entero similar a la india y apoyada en un pedestal. D. Impresión en cartón del troquel de la moneda de una onza (Ocho escudos) no acuñada.

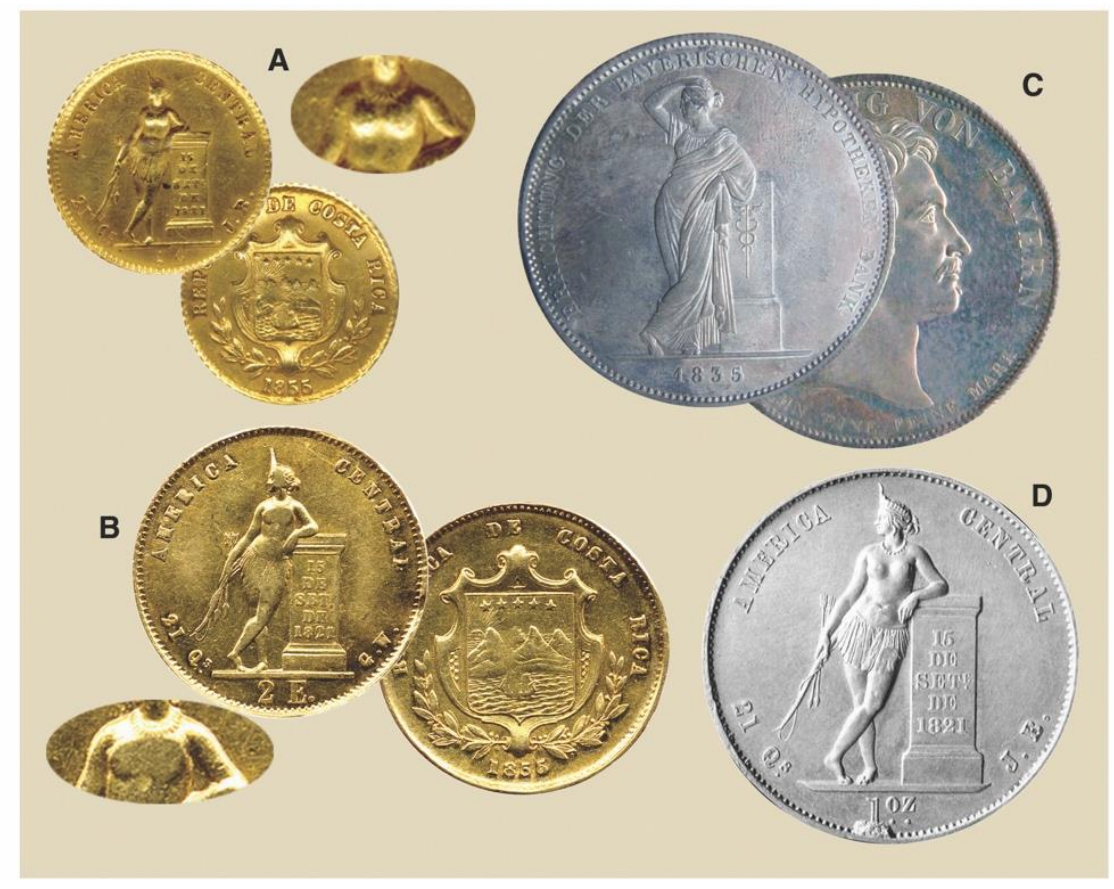

Fuente: Colección privada.

Algunas monedas europeas, como el thaler de 1835 de Bavaria tienen grabada una figura femenina similar a la india de las monedas de Costa Rica, pero vestida del cuello a los pies (Figura. $11 \mathrm{C}$ ). No hay información sobre si el troquel de la moneda alemana fue obra de la misma casa grabadora.

La figura de la india, ataviada solo con una faldilla de aparentes plumas, fue vista como atrevida por algunos sectores de la sociedad costarricense de mediados del siglo XIX (Murillo, 2004, p. 73-74). Posiblemente por esta razón, es frecuente encontrar monedas en las que se aplastaron los senos de la india para dar la impresión de estar cubiertos (Figura 12). Las monedas de oro de la india en pie fueron emitidas entre 1850 y 1864 en valores de $1 / 2$ escudo (1850, 51, 53, 54, 55 y 1864), 1 (1850, 51, 53 y 1855), 2 (1850, 53, 54, 55, 58, 62 , y 1863) y 4 escudos o media onza (1850). Se fabricaron troqueles para monedas de ocho escudos (1 Onza); sin embargo, no fueron acuñadas (Figura 11 D). 
Revista Herencia, Vol. 35 (1), enero-junio, 2022.

\section{Las monedas de la encina}

En la moneda de plata, y según el decreto de 1848, se grabó en el anverso el escudo de armas, que aparece rodeado de trofeos de guerra (Figura 12).

El decreto de emisión de las monedas no especifica los nombres de las ramas entrecruzadas grabadas al pie de los escudos de la moneda de plata y de la de oro. Tal como se menciona para la moneda de 1842 , en la moneda de plata una de las ramas podría corresponder a la palma de la palmera datilera y la otra se asemeja al mirto europeo, por las hojas pequeñas en grupos y los frutillos pedunculados (Figura 12). Otra alternativa podría ser que una de las ramas corresponda al laurel europeo (Laurus nobilis) de uso frecuente en monedas del mundo y símbolo de victoria, mérito, o realeza, que posee hojas de mayor longitud que el mirto, así como frutillos pedunculados (Vargas-Zamora y Gómez-Laurito, 2004, p. 165). Una corona de laurel es frecuente en bustos de monarcas grabados en monedas, como en el de Carlos IV (Figura 3 B).

Figura 12. Monedas de la encina. Anverso: Escudo de la República de Costa Rica, con trofeos de guerra y dos ramas cruzadas en la base, una palma y otra posiblemente de mirto, laurel, u olivo. Reverso: árbol de encina (Quercus sp). A. Un cuarto de Peso (1/4 P $\left.\mathrm{P}^{\circ}\right), 1850,6.4$ g. 24 mm.10 D $20 \mathrm{G}$ (903 milésimas de plata). J. B. (Juan Barth). B. Veinticinco centavos (25 C $)$, 1875, 6.25 g, 24 mm 9 D. (750 milésimas de plata), G.W. (Guillermo Witting).

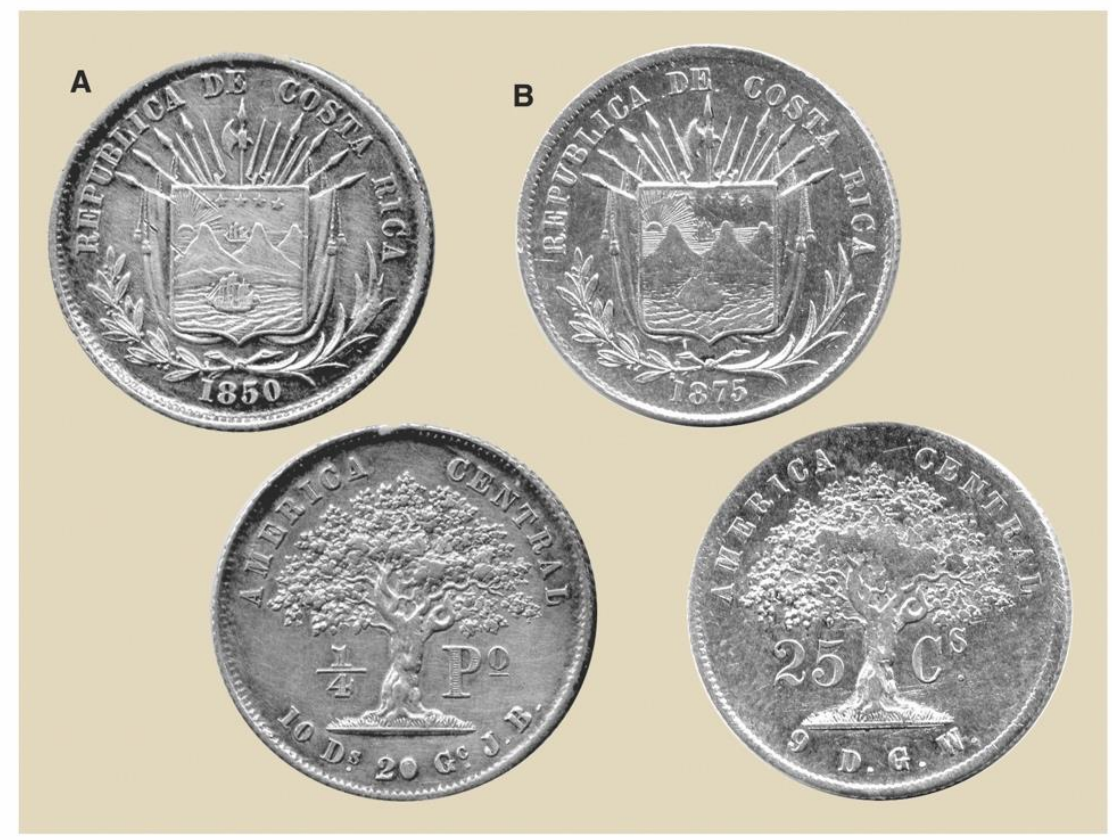

Fuente: Colección privada.

En el reverso de la moneda de plata destaca la escogencia de un árbol de encina o roble (Figura 12). Estos árboles, del género Quercus, con sus características bellotas, frecuentes en Europa y en América, son importantes en la mitología de varias naciones europeas. Desde tiempos bíblicos cuando Abraham recibe a los emisarios de Dios en el encinar de Mamré (Génesis 18, 4, Se os traerá un poco de agua, os lavaréis los pies y reposaréis a la 
Revista Herencia, Vol. 35 (1), enero-junio, 2022.

sombra de este árbol) se asocia a las encinas con la hospitalidad. La madera de encinas y robles es preferida por su fortaleza para la construcción de buques y edificios, así como para toneles de vino y los frutos (bellotas) se usan como alimento (Bocsi et al. 2021). Los encinares eran bosques abundantes en la Costa Rica de mediados del siglo XIX. Quizá, la especie local, Quercus salicifolia, pudo servir de modelo para la moneda (Vargas-Zamora, 2014, p. 43).

Además, se ha interpretado (Vargas-Zamora, 2014, p. 42) que la representación de una encina en la moneda quizá tenía la intención de transmitir el mensaje de una Costa Rica fuerte y hospitalaria. Un mensaje como ese era importante a mediados del siglo XIX cuando el país estaba promoviendo la colonización por parte de inmigrantes europeos, quienes posiblemente estaban familiarizados con el significado de estos árboles, como varios artesanos, profesionales y naturalistas alemanes que se radicaron en el país (Hilje-Quirós, 2013). Entre ellos estaban el ingeniero de minas Johan (Juan) Barth y el Dr. Wilhelm (Guillermo) Witting, quienes luego serían oficiales de la Casa de Moneda y estamparon sus iniciales (J. B. y G.W.) en las monedas.

Las monedas de la encina fueron emitidas entre 1850 y 1862 en denominaciones de 1/16 $(1850,1855$, y 1862$), 1 / 8(1850,1853$, y 1855$)$ y $1 / 4$ de peso $(1850,1853$, y 1855$)$. En 1864 se sustituyó el sistema de los reales y escudos por el sistema decimal ( 1 Peso $=100$ centavos). Entre 1864 y 1875 se hicieron emisiones con el símbolo de la encina y en valores de $5(1865,69,70,71,72$, y 1875), $10(1865,68,70,72$, y 1875), $25(1864,65$, у 1875) у 50 centavos $(1865,66,67,70,72$, y 1875$)$.

En lo que restaba del siglo XIX la emisión de monedas por la Casa de Moneda no fue suficiente para satisfacer la demanda provocada por la creciente producción cafetalera y el auge del comercio, especialmente a raíz de la apertura del ferrocarril al Caribe a fines de siglo.

\section{Conclusiones}

Durante la época colonial, la escasez de moneda emitida por las principales cecas del imperio español fue la norma en Costa Rica y las semillas de cacao fueron utilizadas como moneda. Después de la Independencia en 1821 y hasta mediados del siglo XIX, el país hizo esfuerzos por acuñar moneda propia y habilitar moneda extranjera mediante resellos que certificaran su calidad de acuerdo con las leyes vigentes.

El retiro de las macuquinas en 1849 fue pionero en América Central. También destaca el país en la emisión de varios tipos de monedas con motivos botánicos, como una palmera, una planta de tabaco, un arbusto de café en las mariquitas y un árbol de encina. La escogencia de estas especies estaba asociada a su importancia en la economía, o como símbolos para promover la imagen del país. Es significativa la emisión de la primera moneda conmemorativa y la inclusión, en esta y en monedas de oro de la República, de figuras femeninas como representación del país y de América. El grabado de dos ramas entrelazadas al pie del escudo de armas, o enmarcando el valor de la moneda, es común en monedas del mundo. En las de Costa Rica una rama se asemeja a una palma y la otra posee

ISSN: 1659-0066 
Revista Herencia, Vol. 35 (1), enero-junio, 2022.

hojas pequeñas lanceoladas, en grupos, y frutillos pedunculados. Sin embargo, es difícil el atribuir esta última al mirto, al olivo, o al laurel europeo, más aún si la realidad biológica fue modificada por la libertad artística del grabador.

\section{BIBLIOGRAFÍA}

Acuña Ortega, V. H. (1978). Historia económica del tabaco en Costa Rica: época colonial. Anuario de Estudios Centroamericanos, 4, 289-392.

Araya Pochet, C. (1981). La evolución de la economía cafetalera de Costa Rica bajo el monopolio estatal (1821-1851). Avances de Investigación CIHAC, 4, 1-29.

Bocsi, T., Harper, R. W., De Stefano, S., \& Lass, D. (2021). Historical and cultural perspectives of oak trees in the American landscapes. Arboricultural Journal, 2021. DOI 10.1080/03071375.2021.1893220

Bolaños Villalobos, R., y Arrea Siermann, F. (1999). Al occidente del abra: Historia monográfica de Santo Domingo de Heredia. Servitex Flores, S.A. 104 p.

Burzio, H. F. (1958). Diccionario de la Moneda Hispanoamericana. Fondo Histórico y Bibliográfico José Toribio Medina. 454 p.

Carranza Astúa, J. (2014). Apéndice del libro Historia de los Billetes de Costa Rica 18582012. J. Carranza. 84 p.

Chacón Hidalgo, M. B. (2007). Monedas de cecas españolas reselladas en Costa Rica después de la Independencia. En Arévalo González, A. (Ed). Pp. 1129 -1141. Tomo II. Actas XIII Congreso Nacional de Numismática (Cádiz, 22-24 de octubre, 2007).

Chacón Hidalgo, M. B. (2008). El cacao como moneda oficial en la Costa Rica del siglo XVIII. NVMISMA 252, 137-147.

Chacón Hidalgo, M. B. (2018). Historia de la Casa de Moneda de Costa Rica en los primeros años de su fundación. Fundación Museos Banco Central de Costa Rica. 128 p.

Detsi-Diamanti, Z. (2006). Politicizing aesthetics. The politics of violence and sexuality in colonial and revolutionary representations of America as an Indian woman. The AnacronisT, 12, 61-78.

Fernández Guardia, R. (2002). Costa Rica en el Siglo XIX: Antología de viajeros. Editorial de la Universidad Estatal a Distancia. 495 p.

Gobierno de Costa Rica. (1862). Colección de Leyes Decretos y Ordenes expedidos por los supremos poderes Legislativo y Ejecutivo de Costa Rica, en los años 1845 y 1846. Tomo IX. Imprenta de La paz. 400 p. 
Revista Herencia, Vol. 35 (1), enero-junio, 2022.

Gurdián Montealegre, R. (1996). Contribución al estudio de las monedas de Costa Rica. $2^{\text {da }}$ edición. Litografía e Imprenta LIL. 190 p.

Harden, J. D. (1995). Liberty caps and Liberty trees. Past and Present, 146, 66-102.

Hilje Quirós, L. (2013). Trópico agreste: La huella de los naturalistas alemanes en la Costa Rica del siglo XIX. Editorial Tecnológica de Costa Rica. 865 p.

Jara, C. (2007). Central American provisional and provincial mints. Research of the mint's operative in Honduras, Nicaragua and Costa Rica between 1822 - 1825. Vol. 1. History and coin attributions. Editorial Medinensis. 196 p.

Jiménez, M. J. (1902). Cuadros de costumbres, III. Fiestas Reales. Revista de Costa Rica en el Siglo XIX, 1, 87-93.

Konig, H. J. (2014). La función de las imágenes en el proceso de construcción de naciones latinoamericanas. En Schuster, S. (Ed). (Pp. 1-28). La nación expuesta. Cultura visual y procesos de formación de la nación en América Latina. Editorial Universitaria de Santiago, Bogotá.

León, J. (2001). Patrones generales del comercio marítimo por el Pacífico: mercados y rutas 1700-1850. Revista de Historia, 43, 289-346.

León Saénz, J. (2002). Evolución del comercio exterior y del transporte marítimo de Costa Rica. Colección Historia de Costa Rica No. 7. Editorial de la Universidad de Costa Rica. 380 p.

Lines, J. (1946). Libre Crezca Fecundo. Revista del Banco Nacional de Seguros, 5, 7-17.

McLeod, P. (1996). Auge y estancamiento de la producción de cacao en Costa Rica 166095. Anuario de Estudios Centroamericanos, 22, 83-107.

Monge Alfaro, C. (1962). Historia de Costa Rica. Imprenta Trejos Hnos. 287 p.

Molina, I. (1988). El país del café: génesis y consolidación del capitalismo agrario en Costa Rica (1821-1890). En, Pp. 187-223. Desarrollo Institucional de Costa Rica: de las sociedades indígenas a la crisis del 30. Ediciones Guayacán.

Molina, I., y Palmer, S. (2017). Historia de Costa Rica. $3^{\text {era }}$ edición. Editorial UCR. 226 p.

Molina Montes de Oca, C. (2005). Y las mulas no durmieron...Los arrieros en Costa Rica. Siglos XVI al XIX. Editorial de la Universidad Estatal a Distancia. 559 p.

Murillo, J. (2004). Historia de las monedas de Costa Rica: Catálogo numismático. Editorial de la Universidad Estatal a Distancia. 236 p.

ISSN: 1659-0066 
Revista Herencia, Vol. 35 (1), enero-junio, 2022.

Raymond, W. (1937). The gold coins of North and South America. Wayte Raymond Inc. $102 \mathrm{p}$.

Ruiz López, J. D. (2020). Presencia de elementos vegetales en acuñaciones de la Hispania Ulterior. Hécate, 7, 20 - 33.

Sáenz Maroto, A. (1970). Historia agrícola de Costa Rica. Publicaciones de la Universidad de Costa Rica. Serie Agronomía No. 12. Ciudad Universitaria Rodrigo Facio. 1087 p.

Sedwick, D., y Sedwick, F. (2007). The practical book of cobs. $4^{\text {ta }}$ edición. D.F. Sedwick. Florida. $254 \mathrm{p}$.

Solera Rodríguez, G. (1955). Símbolos nacionales. Librería e Imprenta Atenea. 99 p.

Soley Güell, T. (1975). Compendio de historia económica y hacendaria de Costa Rica. $2^{\text {da }}$ edición. Biblioteca Patria No. 12. Editorial Costa Rica. 138 p.

Thiel, B. A. (1902). Monografía de la población de Costa Rica en el siglo XIX. Revista de Costa Rica en el Siglo XIX, 1, 1 - 52.

Valerio Garita, J. (2019). Las monedas de la segunda administración de Braulio Carrillo. Editorial Tecnológica de Costa Rica. 195 p.

Vargas Zamora, J. A. (2008). A 160 años de la fundación de la República de Costa Rica; sus primeras monedas de oro (1850-1864). Herencia, 21, 89 - 120.

Vargas Zamora, J. A. (2014). Una encina (Quercus sp.) en monedas y billetes de Costa Rica (1848-1948). Reflexiones, 93, 35 - 53.

Vargas Zamora, J. A. (2020). Boletos de café y fichas de empresas: herencias coleccionables. Herencia, 33, $27-51$.

Vargas Zamora, J. A., y Gómez Laurito, J. (2004). Botánica y Numismática: las plantas en las monedas de Costa Rica (1709 -2004). Lankesteriana, 4, 155 - 168.

Vargas Zamora, J. A. y Gómez-Laurito, J. (2006). Palmeras, palmas y mirtos en monedas de Costa Rica (1825-1951). Lankesteriana, 6, 65 - 71.

Vargas Zamora, J. A., y Murillo Rivera, J. (2013). El escudo del Estado de Costa Rica (1840) en el nuevo billete de 1.000 colones (2009). Reflexiones, 92, 9 - 22.

Vargas Zamora, J. A. y Chacón Hidalgo, M. B. (2016). Del genio a las indias: medallas y monedas proclamaron nuevos gobiernos en Costa Rica (1821-1850). Reflexiones, 95, 51 - 71 . 
Revista Herencia, Vol. 35 (1), enero-junio, 2022.

Vargas Zamora, J. A., Chacón-Hidalgo, M. B. y Sánchez-Chaves, J. I. (2018). Las pesetas españolas reselladas en Costa Rica (1845). Fundación Museos del Banco Central de Costa Rica. Impresiones Unicornio. 64 p.

Vargas Zamora, J. A., Chacón-Hidalgo, M. B. y Sánchez-Chaves, J. I. (2021). El resello de las macuquinas en Costa Rica (1846). Fundación Museos del Banco Central de Costa Rica. Impresiones Unicornio. 88 p.

Vega Jiménez, P. (1991). De la banca al sofá. La diversificación de los patrones de consumo en San José (1857-1864). Revista de Historia, 24, 53 - 85.

Villalobos Rodríguez, J. H., Chacón de Umaña, L. A., y Sáenz Carbonell, J. F. (2000). Braulio Carrillo. El estadista. Tomo II. Imprenta Nacional. 619 p.

Wallace, H. (1966). Central American coinage since 1821. H. Wallace. Weslaco. 125 p. 
Revista Herencia, Vol. 35 (1), enero-junio, 2022. 